\title{
CAMA
}

Centre for Applied Macroeconomic Analysis

\section{Endogenous fertility, externality and phase out of pensions}

\section{CAMA Working Paper 96/2020 November 2020}

Amol

Department of Economics, University of Minnesota

\section{Monisankar Bishnu}

Economics and Planning Unit, Indian Statistical Institute, Delhi

Centre for Applied Macroeconomic Analysis, ANU

\section{Harsh Kumar}

Economics and Planning Unit, Indian Statistical Institute, Delhi

\section{Tridip Ray}

Economics and Planning Unit, Indian Statistical Institute, Delhi

\section{Abstract}

This paper exploits a well accepted inefficiency that arises out of Pay-As-You-Go (PAYG) pensions itself to phase it out in a Pareto way. The positive externality of having children in a PAYG pension system is carefully utilized to phase the pensions out. In a model with endogenous fertility the paper first confirms the sub-optimality of parent's choices and recommends an intergenerationally balanced childcare subsidy to correct for the externalities in a PAYG system. However, if PAYG pension program needs to be dismantled for various reasons, it can be phased out from there infinite time and, more importantly, just by exploiting the above mentioned externalities keeping the Pareto conditions intact. This phase out plan under Pareto satisfies all the standard efficiency criteria suggested in the literature when fertility is endogenous. 


\section{Keywords}

Endogenous fertility, Fertility externality under PAYG pensions, Phase out of PAYG pensions, Pareto efficiency

\section{JEL Classification}

\section{Address for correspondence:}

(E) cama.admin@anu.edu.au

\section{ISSN 2206-0332}

The Centre for Applied Macroeconomic Analysis in the Crawford School of Public Policy has been established to build strong links between professional macroeconomists. It provides a forum for quality macroeconomic research and discussion of policy issues between academia, government and the private sector.

The Crawford School of Public Policy is the Australian National University's public policy school, serving and influencing Australia, Asia and the Pacific through advanced policy research, graduate and executive education, and policy impact. 


\title{
Endogenous Fertility, Externality and Phase Out of Pensions*
}

\author{
$\mathrm{Amol}^{\dagger}$ \\ Monisankar Bishnu ${ }^{\ddagger}$ \\ Harsh Kumar§ \\ Tridip Ray
}

November 4, 2020

\begin{abstract}
This paper exploits a well accepted inefficiency that arises out of Pay-As-You-Go (PAYG) pensions itself to phase it out in a Pareto way. The positive externality of having children in a PAYG pension system is carefully utilized to phase the pensions out. In a model with endogenous fertility the paper first confirms the sub-optimality of parent's choices and recommends an intergenerationally balanced childcare subsidy to correct for the externalities in a PAYG system. However, if PAYG pension program needs to be dismantled for various reasons, it can be phased out from there in finite time and, more importantly, just by exploiting the above mentioned externalities keeping the Pareto conditions intact. This phase out plan under Pareto satisfies all the standard efficiency criteria suggested in the literature when fertility is endogenous.
\end{abstract}

Key words: Endogenous fertility, Fertility externality under PAYG pensions, Phase out of PAYG pensions, Pareto efficiency

${ }^{*}$ The authors would like to thank David de la Croix, Dirk Krueger and Morten Ravn for many helpful comments and suggestions.

\footnotetext{
${ }^{\dagger}$ Department of Economics, University of Minnesota. Email: amol0002@umn.edu

${ }^{\ddagger}$ Economics and Planning Unit, Indian Statistical Institute, Delhi; CAMA (ANU); CEPAR. Email: mbishnu@isid.ac.in

${ }^{\S}$ Economics and Planning Unit, Indian Statistical Institute, Delhi. Email: harshk7797@gmail.com

`Economics and Planning Unit, Indian Statistical Institute, Delhi. Email: tridip@isid.ac.in
} 


\section{Introduction}

For a plethora of reasons, sustainability of the age-old Pay-As-You-Go (PAYG) pensions has been a matter of concern for the last few decades. Many countries with PAYG type pensions, an important instrument which has served as a great support to the old for decades, are pursuing reforms to downsize the program. Even the extreme form of it, the elimination of the program, has also been discussed extensively in the literature as well as in the policy circle. Possibly the most important issue here is whether this elimination can be done in a Pareto way. The broad conclusion is that it is generally difficult to compensate the first generation of pensioners for the loss incurred without making at least one later generation worse off. The literature that deals with the transition from PAYG to a funded pension system is very rich and eliminating PAYG type pensions in a Pareto way remains to be a big challenge, especially when the demographic changes are not in favor of continuing this program. In this paper we present a novel mechanism that exploits a well accepted externality effect, spawning from having children in a contributory public pension system, to phase out pensions in a Pareto way. Thus, we contribute to this rich literature by showing that PAYG type pensions can be phased out in a Pareto way and, interestingly, by capitalizing on an inefficiency that arises from the PAYG pensions itself.

A severe budgetary pressure that PAYG type pensions are facing is mainly due to a demographic shift in the developed countries, typically the home of PAYG. A fall in fertility has coincided with the increase in size of the pension system (Boldrin, De Nardi and Jones (2015)), raising concerns over its feasibility. Moreover, an increase in longevity of retired people is worsening the budgetary concerns further. ${ }^{1}$ From a theoretical perspective too, the celebrated Aaron - Samuelson results confirm that the PAYG pension regime is welfare reducing if the economy is dynamically efficient (Aaron (1966)) where PAYG return is dominated by the market return. ${ }^{2}$ There are some other concerns including behavioral ones that also go against this age-old instrument. ${ }^{3}$ All these create an impression that, given the present state of affairs, a PAYG may

\footnotetext{
${ }^{1}$ How to adjust the features of the social security scheme to changes in longevity has been discussed by Mulligan and Sala-I-Martin (2003, 2004) and Andersen (2008), among others.

${ }^{2}$ According to Abel et al. (1989), U.S. and other OECD countries are dynamically efficient. Mankiw (1995) mentions: “... excessive capital accumulation is not a practical concern for policymakers. Actual economies appear to have less capital than the Golden Rule level." Barbie, Hagedorn and Kaul (2004) presents a test criterion based on Zilcha (1991) and robust evidence that the U.S. economy is dynamically efficient. Thus, following the literature, we assume the economy is not overaccumulating capital and PAYG pension is return dominated.

${ }^{3}$ Admittedly pension programs have many critiques, some of which are purely on philosophical grounds. Possibly the most important one is a myopia or present bias in consumption. Individuals differ in their tastes and the government may not be the best judge of what is in their best interest (see Friedman (1962), Feldstein (2005)). Surely there are things that an individual would enjoy more and would like to spend on when she is young rather than when she is old. Social security benefits thus infringe on an individual's liberty by changing her preferences. A myopic agent has an inherent preference towards consuming more when young than old. A paternalistic intervention like public pension based on the value judgement that the myopic agents save less for their old age than they ideally should, will admittedly increase the old age consumption of the agent (for a review of the literature dealing with the rationale for social security via its effect on savings see de la Croix and Michel (2002). Social security in the presence of time inconsistency have been discussed extensively (see for example, Imrohoroğlu, İmrohoroğlu and Joines (2003), Caliendo (2011)). Andersen and Bhattacharya (2011) revisits the role played by myopia in generating a rationale for PAYG pension in dynamically efficient economies. Also, provision of old age benefits distorts retirement behavior and the tax that is imposed on the working population may distort labor supply (see Feldstein (1985)).
} 
not be desirable on its own unless it serves some other purpose. ${ }^{4}$

To the best of our knowledge, this paper is the first attempt to show a complete phaseout of pensions, under both exogenous and endogenous factor prices frameworks, when fertility choices are endogenous. The literature on phasing out PAYG pensions or moving to a fully funded one from PAYG type pensions is substantially rich. ${ }^{5}$ Our framework that models fertility as an endogenous choice and our mechanism that exploits externalities to phase out PAYG pensions in a Pareto way, are substantially different from the existing analyses. To be precise, the model exploits an externality that is associated with the PAYG pension system itself, arising through endogenous fertility decisions. More importantly, this plan which decreases PAYG pension tax in subsequent periods and pension is phased out in finite time, satisfies the standard efficiency conditions designed in the recent literature when fertility is endogenous. Two recent papers that are somewhat similar in spirit to our work in terms of phasing PAYG pensions out in a Pareto way but using a framework of education and pension along with exogenous choice of fertility are Andersen and Bhattacharya (2017) and Bishnu et al. (2018). While under the assumption of exogenous factor prices, the first paper uses human capital externalities to phase out pensions starting from the complete market allocation (the best possible allocation when a perfect credit market to borrow funds for education is present), the second paper characterizes the optimal path of phasing out pensions starting from an incomplete market, using only the market inefficiency.

Let us first explain the externality that has been used in this analysis to phase out pensions. Benefits of having more children are enjoyed by the society if there is a publicly funded contributory system such as the PAYG since having a child broadens and deepens the pension tax base. An individual agent however does not take this benefit into account fully. Since this increase in the tax base will be shared with all individuals, an individual agent's own share of this increase in old-age pension is very small and imperceptible to her. That is, an individual's decision to have children is driven solely by the direct utility she gets from her children, whereas they have a positive externality on the society. This particular form of externality was recognized

\footnotetext{
4 Apart from shortsightedness of agents as one of the main motives (see for example Kotlikoff (1987), Kaplow(2008)), a benevolent planner can have numerous important reasons behind justifying a social security system. Some of them are income redistribution (see Diamond (1977)), risk sharing between or within generations (see Enders and Lapan (1982), Smith (1982). Sinn (2004) among others), repairing the annuity markets (see Diamond (1977), Feldstein (1990) among others). Krueger and Kubler (2006) analyzed the role of unfunded pensions in the presence of idiosyncratic risks when financial markets are incomplete. Political economy issues and also sustainability of social security have also been extensively analyzed (see for example, Browning (1975), Lambertini and Azariadis (1998), Conesa and Krueger (1999), Cooley and Soares (1999), Azariadis and Galasso (2002), Lancia and Russo (2016), Bishnu and Wang (2017), and for a detail review see Galasso and Profeta (2002)). One more crucial reason can be the need for a balance between two differently directed intergenerational goods, mainly education and pensions. This rich literature started with Pogue and Sgontz (1977), Becker and Murphy (1988), and further enriched by Kaganovich and Zilcha (1999), Boldrin and Montes (2005), and very recently contributed by Docquier, Paddison and Pierre Pestieau (2007), Bishnu (2013), among others (education pension combination has also been used to explain, for example, growth as in Zhang (1995), inequality as in Glomm and Kaganovich (2003)).

${ }^{5}$ See for example, Verbon (1988), Breyer (1989), Breyer and Straub (1993), Fenge (1995), Rangel (1997), Miles (1999), Sinn (2000), Kotlikoff (2002), Lindbeck and Persson (2003), Barr and Diamond (2006) among others.
} 
quite some time ago and is now well-established in the pension-related literature. ${ }^{6}$ While Cigno (1993) termed this as positive externality of children, Folbre (1994) called children as public capital good. This social benefit of children can lead to a free-riding behavior where agents no longer need children for old-age support: they do not need to spend on children as they can avail the benefits of having children through the pension system. Schoonbroodt and Tertlit (2014) also point out the inefficiency of PAYG pensions in the presence of endogenous fertility which is due to the same reason that the costs and benefits of producing children remain unaligned. In an important contribution, van Groezen, Leers and Meijdam (2003) show that PAYG pensions and child subsidy are "Siamese twins", that is, PAYG pensions must be accompanied by child subsidy to handle this externality. Our approach of dealing with the externality is similar to Boldrin and Jones (2002) in the sense that the optimal solution is the cooperative equilibrium where the middle-aged agents jointly determine their old-age pension by choosing the optimal number of their children. To be precise, while the interpretation in Boldrin and Jones (2002) is through the family level, ours is through the societal level. While a significant body of research emphasizes the role of balanced intergenerational transfers, as we have also demonstrated first, given the strain on pure PAYG, we offer the analysis of a complete phaseout of pensions. In particular, we take advantage of this positive social externality of having children and show that in its presence a complete phase out of pensions, as desired when PAYG is return dominated, is clearly possible. Further, throughout this phaseout period, the Pareto condition is never compromised.

When fertility is endogenous, the usual notion of Pareto efficiency is not well-defined. There is a literature that redefines the concept of Pareto efficiency in environments with endogenous fertility. Some of the prominent studies are Golosov, Jones and Tertilt (2007) which proposes the notions of $\mathcal{A}$-efficiency and $\mathcal{P}$-efficiency, Michel and Wigniolle (2007) which proposes RCefficiency, and Conde-Ruiz, Giménez and Pérez-Nievas (2010) which proposes the notion of Millian efficiency. Recently Cordoba and Liu (2018) has investigated the properties of socially optimal allocations in an environment characterized by endogenous fertility along with fixed resources under the Malthusian regime. Generally, efficiency criteria consider either just welfare of born agents or both welfare and population size to compare alternate scenarios. Our Pareto criterion takes care of both welfare and population. During the policy implementation and the subsequent phase out period, no generation is worse off than it was under the PAYG pension system and, at the same time, population never goes below the PAYG level. We also demonstrate that our Pareto criterion obeys all the standard efficiency criteria defined in the context of endogenous fertility.

Let us briefly explain the mechanism that is at work in our paper. From the literature discussing the positive externality of children in a PAYG pension regime we know that any generation can be made better off by implementing a government subsidy scheme. Government subsidy on children lowers the costs of raising children. This provides incentive to individuals to have more children, thus broadening the tax base for their pension benefits. Increase in tax base

\footnotetext{
${ }^{6}$ For a nice and up-to-date discussion of the fiscal externality due to children see Barnett et al. (2018).
} 
for pension benefits was the positive externality of children which was ignored by individual agents and is now taken care of by the subsidy for children. We first show that a government subsidy scheme financed by taxing parents is necessary to handle the externalities of children generated due to the PAYG pension system. However, as mentioned above, our scheme does not stop at just implementing the child care subsidy. The subsidy scheme makes the current generation better off as it has more children and hence higher pensions. Suppose that introducing the subsidy scheme increases the current generation's lifetime utility from $V^{*}$ to $V_{1}>V^{*}$. This increase in current generation's utility allows the government to reduce its pension benefits while ensuring that the utility does not fall below $V^{*}$. Therefore, while satisfying the Pareto criterion of not making any generation worse off than under the PAYG pension system, the government can decrease this generation's pension benefits and hence the next generation's pension tax. Now the next generation faces a lower pension tax and there is a subsidy scheme in place to take care of the externalities of children in a PAYG pension system. Therefore, its utility is greater than the benchmark utility level $V^{*}$ of the PAYG system. So the government can again reduce this generation's pension benefits and hence the following generation's pension tax. As the next generation faces a lower pension tax, the government can keep on decreasing subsequent generations' pension taxes.

We consider two cases: first an illustration with exogenous factor prices and second, a more general framework with endogenous factor prices. For the case of exogenous factor prices, we show that this process of reducing pensions in conjunction with subsidy for correcting the PAYG pension related externalities will lead to a zero pension tax in finite time. Hence, starting from an institutionalized PAYG pension system, we show the existence of a sequence of government subsidy for children and pension taxes which culminates in the complete phaseout of the PAYG pension system. ${ }^{7}$

These intuitive results have been presented finally in a more general setting. We show that the pension reforms described above is robust to the general equilibrium effects too, that is, when the factor prices are endogenous. While this analysis is more involved than its exogenous counterpart, the underlying mechanism is similar. Harnessing the same positive externality of children in a PAYG regime, the government can implement a pension reform in the Pareto-way. At the end of the transition, the economy reaches its optimal steady-state. We characterize this optimal steady-state and show that there exists a path to the optimum such that the transition as well as the steady-state dominate the current steady-state with PAYG pensions. Again by domination, we refer to $\mathcal{P}$-efficiency ensuring that, under the pension reform, no generation has less utility or population than the alternate scenario where this reform was not undertaken. At the optimum, either PAYG pension is positive but gives the same return as private savings, or it hits the zero lower bound and is phased out. In other words, at the optimal steady-state, either the economy achieves the 'golden rule' with the endogenous return on capital $R$ equalling

\footnotetext{
${ }^{7}$ We have computationally verified this phaseout results, namely the evolution of pension, fertility, income and consumption during the policy implementation period till the pension is completely phased out. Also, the phaseout result is robust to introducing human capital and quality-quantity tradeoff as in Galor and Weil (2000) and de la Croix and Doepke (2003). The results are available on request.
} 
the rate of endogenous fertility $n$ which is also the return on the positive PAYG pension, or there is 'underaccumulation' with $R>n$, that is, PAYG is return dominated by the market return. In the case of $R>n$ where PAYG pension hits its zero lower bound, we show that the optimal steady-state must be supported by a subsidy on savings that can incentivize saving in the absence of a PAYG type transfer.

The rest of the paper is organized as follows. Section 2 sets up the model. Section 3 illustrates the basic mechanism and results using a simplified framework with exogenous factor prices. In Section 4, we generalize the results using the general set-up with endogenous factor prices. Section 5 concludes. All the proofs are presented in the Appendix.

\section{The model}

We consider an overlapping generations economy where agents live for three periods. They are young in the first period, middle-aged in the second and old in the third. An agent is born in the first period. She earns wage in the second period, consumes in that period and saves for her old age. She also decides to have children in the second period. Finally, she consumes the returns from her investment in the third period. An agent derives utility from her consumption in the middle age and consumption in the old age. For simplicity, we assume that the agents do not consume anything when young. The agent also derives utility from the number of her children. For notation, we identify a generation by the period when it is in middle age. That is, if an agent was born in period $t-1$ and is of middle age in period $t$, we call her a generation $t$ agent.

We assume that the utility of a generation $t$ agent is given by

$$
u\left(c_{t}^{m}\right)+\beta u\left(c_{t+1}^{o}\right)+v\left(n_{t}\right),
$$

where $c_{t}^{m}$ and $c_{t+1}^{o}$ are agent's consumption in the middle age and old age respectively. The agent discounts her utility from consumption in old age by $\beta$ where $\beta \in(0,1)$. The utility from consumption is given by the function $u($.$) which is assumed to be strictly increasing and concave,$ that is, $u^{\prime}()>$.0 and $u^{\prime \prime}()<$.0 . It also satisfies Inada conditions, that is, $\lim _{c \rightarrow 0} u^{\prime}(c)=\infty$ and $\lim _{c \rightarrow \infty} u^{\prime}(c)=0$. Since fertility is an important issue especially for the analysis of sustainability of PAYG type pensions, we model fertility as endogenous. An agent's number of children is denoted by $n_{t}$. The utility an agent derives from her children is denoted by $v($.$) . We assume$ that $v($.$) also is strictly increasing, concave and satisfies Inada conditions.$

The production function in period $t, f\left(s_{t}, n_{t-1}\right)$, follows constant returns to scale technology with respect to the factors - capital accumulated through the savings of generation $t-1$ agents, $s_{t}$, and labor available in period $t, n_{t-1}$. Further, it satisfies Inada conditions along with the standard concavity assumptions. Factor markets being competitive, equilibrium factor prices are given by their marginal products: $R_{t}\left(s_{t}, n_{t-1}\right)=f_{1}\left(s_{t}, n_{t-1}\right)$ and $w_{t}\left(s_{t}, n_{t-1}\right)=f_{2}\left(s_{t}, n_{t-1}\right)$ where $f_{i}$ represents marginal productivity of the $i$ th factor of production. As we have mentioned above, throughout the paper we assume that at any $t$, the gross return of return on capital in 
the economy is higher than the population growth rate.

The government is present in the economy. Initially, the only role the government plays is that of administering the PAYG pension system. An agent while working in her middle age pays a proportion of her income to support pension for the old. In return, she receives pension support in her old age. In subsequent sections we suggest another role for the government to provide subsidy per child for correcting the pension externalities.

\subsection{The PAYG Regime}

We start with an economy where a pay-as-you-go pension scheme is in place with proportional pension tax at time $t$ given by $\tau_{t}$. An agent pays the pension tax in her middle age and receives pension support $p_{t+1}$ in old age.

For a generation $t$ agent, her middle age budget constraint is given by

$$
c_{t}^{m}+q n_{t}+s_{t+1}=\left(1-\tau_{t}\right) w_{t} .
$$

The agent supplies labor inelastically and earn a wage $w_{t}$. Raising each child has a constant cost $q$ and an agent who has $n_{t}$ children bears a cost of $q n_{t}$. A proportion $\tau_{t}$ of the earning $w_{t}$ is paid to the government as tax for pension benefits to present old. Agent's saving for her old age is denoted by $s_{t+1}$.

In the old age the agent survives on her savings in the middle age which earns a gross interest rate $R_{t+1}>1$, as well as pension support $p_{t+1}$ from government. Thus, the agent's old age budget constraint is given by

$$
c_{t+1}^{o}=s_{t+1} R_{t+1}+p_{t+1} .
$$

The government balances its budget in every period. In period $t+1$ it funds pension to the old, $p_{t+1}$, by taxing the earnings of $n_{t}$ middle-aged of generation $t+1$ at the rate $\tau_{t+1}$. Thus the government's balanced budget constraint in period $t+1$ is given by

$$
p_{t+1}=\tau_{t+1} n_{t} w_{t+1}
$$

\section{An Illustration (with Exogenous Factor Prices)}

In this section we illustrate our mechanism in a simplified framework where factor prices are exogenously given, that is, $w_{t}=w$ and $R_{t}=R$ for all $t .{ }^{8}$ We return to the general case with endogenous factor prices in the next section.

\footnotetext{
${ }^{8}$ The importance of general equilibrium effects for sustaining intergenerational transfers is well documented in the literature (see, for example, Cooley and Soares (1999) and Boldrin and Rustichini (2000)).
} 


\subsection{Suboptimal Fertility in a PAYG Regime}

We first demonstrate that atomistic individual's fertility choice is suboptimal in our standard PAYG regime.

\section{Individualistic choice of fertility}

In this standard PAYG regime an atomistic individual's consumption and fertility choices are given by the solution to the following problem of a generation $t$ agent:

$$
\begin{aligned}
& \max _{\left\{s_{t+1}, n_{t}\right\}} u\left(c_{t}^{m}\right)+\beta u\left(c_{t+1}^{o}\right)+v\left(n_{t}\right) \\
& \text { subject to } \\
& \quad c_{t}^{m}=\left(1-\tau_{t}\right) w-q n_{t}-s_{t+1}, \\
& c_{t+1}^{o}=s_{t+1} R+p_{t+1} .
\end{aligned}
$$

Individuals act atomistically and do not take the government's pension budget constraint into account while solving their problem. The change in tax base to fund the pension due to one individual's fertility choice will be small and imperceptible to the individual. Therefore, parents take into account only the direct utility they enjoy from the quantity of their children and ignore the pension benefits they receive as a result of investing in the number of their children. For this reason they treat $p_{t+1}$ as exogenously given while solving problem (A).

The solution to problem (A) is characterized by the middle age and old age budget constraints and the following first order conditions with respect to $s_{t+1}$ and $n_{t}$ respectively:

$$
\begin{aligned}
& u^{\prime}\left(c_{t}^{m}\right)=\beta R u^{\prime}\left(c_{t+1}^{o}\right), \\
& u^{\prime}\left(c_{t}^{m}\right) q=v^{\prime}\left(n_{t}\right) .
\end{aligned}
$$

The first condition is the standard Euler equation. An agent equates the marginal utility from consumption in middle age to that in old age. The second condition equates the marginal loss in consumption utility from having an extra child to the marginal gain in utility from having an extra child. It ignores the gain in utility due to increase in pension support working through the government's budget constraint.

\section{Optimal choice of fertility}

An agent does not internalize her pension benefits and takes $p_{t+1}$ as exogenous. This creates the well-documented free-riding problem (van Groezen, Leers and Meijdam (2003)): having children has a positive externality of increasing the tax base for pension support which an individual agent does not take into account. The optimal fertility choice should internalize this positive externality. Alternatively, in the spirit of Boldrin and Jones (2002), the suboptimal individual choices can be interpreted as a competitive equilibrium where each agent takes as given the pension available to her and makes her fertility choice as the best response to maximize 
her utility. Then the optimal solution can be viewed as a cooperative equilibrium where the middle-aged agents jointly determine their old-age pension by choosing the quantity of their children. So in the agent's optimal choice problem, pension in the old age budget constraint should show up as $\tau_{t+1} n_{t} w$ instead of an exogenous $p_{t+1}$. An individual agent can control her pension in collaboration with other agents in the optimal solution. Thus, following Boldrin and Jones (2002) the optimal choices are given by the solution to the following problem:

$$
\begin{gathered}
\max _{\left\{s_{t+1}, n_{t}\right\}} u\left(c_{t}^{m}\right)+\beta u\left(c_{t+1}^{o}\right)+v\left(n_{t}\right) \\
\text { subject to } \\
\quad c_{t}^{m}=\left(1-\tau_{t}\right) w-q n_{t}-s_{t+1}, \\
c_{t+1}^{o}=s_{t+1} R+\tau_{t+1} n_{t} w .
\end{gathered}
$$

In the optimal solution, an agent takes her pension support as endogenous where its level is affected by the choice of her fertility. It is the product of the next period pension tax $\tau_{t+1}$, each child's earning $w$ and her number of children $n_{t}$. The solution to the problem (B) is given by the two budget constraints of middle age and old age and the following first order conditions with respect to $s_{t+1}$ and $n_{t}$ respectively:

$$
\begin{aligned}
& u^{\prime}\left(c_{t}^{m}\right)=\beta R u^{\prime}\left(c_{t+1}^{o}\right), \\
& u^{\prime}\left(c_{t}^{m}\right) q=\beta u^{\prime}\left(c_{t+1}^{o}\right) \tau_{t+1} w+v^{\prime}\left(n_{t}\right) .
\end{aligned}
$$

The first condition is the standard Euler equation where the agent smoothens her optimal consumption. The second condition however now includes the marginal gain in utility through increase in pension, unlike the condition under atomistic choice. The second condition equates the marginal disutility from having an extra child to the marginal gain in utility from two channels. First, there is a direct gain in utility through an increase in number of children as appears under atomistic choice too. Additionally, having more children increases the number of taxpayers in next generation who fund the pension support for current generation.

\section{Suboptimality of individualistic fertility choice}

We denote the optimal fertility level of children which solves problem (B) by $n_{t}^{o p t}$. Fertility level which solves an atomistic individual's problem (A) is denoted by $n_{t}^{\text {ind }}$ with the superscript ind corresponding to individual's choices. In the following proposition we establish that when atomistic agents do not internalize the pension benefits, the fertility choice is suboptimal.

Proposition 1. In a standard $P A Y G$ regime an agent's utility is lower under individualistic decision-making than under optimal decision-making. The suboptimality is generated by lower fertility choice under individualistic decision-making, that is, $n_{t}^{\text {opt }}>n_{t}^{\text {ind }}$.

Proof. See Appendix A.1. 


\subsection{Government Subsidy to Achieve the Optimal Choices}

As proved in Proposition 1, agent's individualistic choices are suboptimal in fertility. To achieve the optimal fertility level the government must provide incentives to agent to have more children and these incentives may come in the form of a Pigouvian subsidy. Since children are normal goods in this model, lowering their effective cost will lead agents to have more children. We will show that the government can achieve the optimal choices by providing a subsidy on child care which is financed by a lump sum tax.

Suppose in period $t$, the government provides a child care subsidy of $\phi_{t}$ per child. It finances this subsidy by a lump sum tax $T_{t}$. The government's budget constraint is given by

$$
T_{t}=\phi_{t} n_{t} .
$$

An agent's effective cost of her child care is now $\left(q-\phi_{t}\right)$. However, she faces an extra tax burden $T_{t}$ which she takes as exogenous. A generation $t$ agent now faces the following problem:

$$
\begin{aligned}
& \max _{\left\{s_{t+1}, n_{t}\right\}} u\left(c_{t}^{m}\right)+\beta u\left(c_{t+1}^{o}\right)+v\left(n_{t}\right) \\
& \text { subject to } \\
& \quad c_{t}^{m}=\left(1-\tau_{t}\right) w-T_{t}-\left(q-\phi_{t}\right) n_{t}-s_{t+1}, \\
& \quad c_{t+1}^{o}=s_{t+1} R+p_{t+1} .
\end{aligned}
$$

As before, the agent takes pension benefit $p_{t+1}$ as exogenous and the government's balanced budget constraint requires

$$
p_{t+1}=\tau_{t+1} n_{t} w .
$$

The subsidy on children reduces the marginal cost of child care, thus changing the first order conditions. The solution to this problem is given by the following first order conditions:

$$
\begin{aligned}
& u^{\prime}\left(c_{t}^{m}\right)=\beta R u^{\prime}\left(c_{t+1}^{o}\right), \\
& u^{\prime}\left(c_{t}^{m}\right)\left(q-\phi_{t}\right)=v^{\prime}\left(n_{t}\right) .
\end{aligned}
$$

Comparing the first-order conditions (2) and (3) the following proposition defines the child care subsidy to match the optimal choices.

Proposition 2. In the presence of PAYG pensions, optimal subsidy on child care, $\phi_{t}$, for which agent's individualistic choices match the optimal choices is characterized by

$$
R \phi_{t}=\tau_{t+1} w
$$

Equation (4) implies that the optimal child care subsidy should be such that its value should add up to the present value of the child's contribution towards the agent's pension. Hence, 
we establish that the government can take care of the pension externality of children by an appropriate child care subsidy. One noteworthy point is that child allowance is positive only if current generation's pension is positive, that is, $\tau_{t+1}>0$. Since the only reason for subsidy in this model is to correct for the positive externality generated by a child in a PAYG pension system, the subsidy is not required if the agent does not receive a pension support in old age.

An important observation is worth mentioning here. The above result confirms the "Siamese twins" results of van Groezen, Leers and Meijdam (2003) and van Grozen and Meijdam (2008). In a model with fertility and pension, they prove the interdependence between child care subsidy and pension in the presence of a market failure, precisely when externalities in public pension via fertility are ignored by the competitive equilibrium. In fact a somewhat conceptually similar argument is also valid but gone unnoticed in Boldrin and Montes (2005) which shows that in the absence of a perfect credit market to borrow funds for education, an education-pension package can well replicate the complete market allocations, that is, a balance between the two oppositely directed intergenerational goods is a must as a solution. In Rangel (2003) too the interdependence between the forward and the backward intergenerational goods is very clear.

As the above proposition shows, in the presence of PAYG pensions, the government can always make an improvement by implementing a child care subsidy scheme. This intergenerational arrangement will result in a rise in fertility to its optimal level. However, the concern is with the PAYG pension itself, as we have discussed in detail in the introduction. Thus, after achieving the optimal choices, an important and timely relevant issue is to show a gradual phase out of pensions in a Pareto way given the fiscal arrangements that we have in our setup. We devote the next subsection to this much discussed issue of phasing pensions out in a Pareto way. ${ }^{9}$

\subsection{Phase Out of PAYG Pension}

Interestingly, the externality associated with PAYG pensions itself gives us a way to address the phase out issue in a Pareto way. Since each generation can be made better off by the government subsidy scheme as discussed above, their pensions can be decreased in conjunction with correcting their fertility choice so that they get the same utility that they would have enjoyed under a PAYG regime with no government subsidy. Therefore, the PAYG-only regime (that is, the PAYG regime without child care subsidy) provides the benchmark. The government can correct the pension externality using the fiscal instruments mentioned above and take the agent's utility to a higher level. But the government is not necessarily obliged to adopt this policy, rather it can curtail pensions to some extent while ensuring that the agent gets the benchmark utility of PAYG-only regime. Crucially, we observe that once one generation pays a lower pension tax,

\footnotetext{
${ }^{9}$ One not so interesting but technically plausible case is that government subsidy increase fertility to such an extent that the fertility rate $n_{t}^{o p t}$ (which is also the rate of growth of population) exceeds the rate of return on capital $R$. Then the pension system may remain desirable as its return exceeds the return from investment in capital market and then there may not be sufficient reason behind phasing out PAYG pension. However, we assume that such an implausible jump in fertility does not occur. Therefore, our goal is to phase out PAYG pensions precisely when market return is higher than the return from PAYG pension.
} 
the subsequent generations will have to pay lower pension taxes too and, eventually, pensions will be phased out in the process. Therefore, we use an inefficiency associated with the pension system itself (that arises through fertility) to phase out the pension system. To the best of our knowledge, this paper is the first attempt of phasing out pension using an inefficiency that generates from PAYG pension itself. Additionally, the recommendation of balancing intergenerational transfers, as suggested in the broad literature, can also be avoided especially when sustainability PAYG is a serious concern.

We now formally present our policy prescription. Consider a generation $t$ agent whose indirect utility under the PAYG-only regime is denoted by $V^{*}$. This is the benchmark utility and the government ensures that each subsequent generation gets at least as much as $V^{*}$ throughout the phaseout period. We denote the optimal and individualistic utilities for a generation $t$ agent who faces a pension tax $\tau_{t}$ and whose children face a pension tax $\tau_{t+1}$ by $V^{o p t}\left(\tau_{t}, \tau_{t+1}\right)$ and $V^{i n d}\left(\tau_{t}, \tau_{t+1}\right)$ respectively. Our scheme works as follows.

Let us start from a steady-state where a generation $t$ agent pays a pension tax $\tau_{t}=\tau$, and, whose children pay a pension tax $\tau_{t+1}=\tau$ so that $V^{i n d}(\tau, \tau)=V^{*}$. First, a government subsidy scheme increases the utility of generation $t$ agents by aligning their fertility choice with the optimal choice while maintaining the children's pension tax rate at $\tau$. The government can always achieve this higher utility level by implementing the subsidy scheme discussed in Proposition 2. However, in order to phase the pensions out, the government must reduce the pension tax in period $t+1$. In part (a) of the following proposition we show that the government can do this while ensuring that the generation $t$ agent is no worse off than it was under the PAYG-only regime by taking advantage of the increased utility in the subsidy regime.

Note that both the policy experiments - child care subsidy as well as reduced rate of pension benefits - are introduced to the generation $t$ agent. While the optimal subsidy increase the number of children, the reduced rate of pension benefits would result in a lower fertility as children are normal goods in this model. The question is the net impact on fertility. A related issue is the net effect on total pension benefits of the generation $t$ agent, $p_{t+1}=\tau_{t+1} n_{t} w$. In part (b) of the following proposition we argue that the net effects on fertility as well as total pension benefits are positive. The reason is that the government is affecting the fertility decision of the generation $t$ agent without changing her pension tax rate $\tau_{t}$. Since under individualistic choices the agent chooses her fertility and saving for a given pension tax and total pension benefits, any changes keeping total pension benefits constant or lower would decrease her utility. So total pension benefits must increase. As $\tau_{t+1}$ falls, it follows that the net effect on fertility is also positive.

Proposition 3. Let $V^{\text {ind }}(\tau, \tau)=V^{*}$.

(a) The government can reduce the pension tax of the generation $t+1$ agent to $\tau_{t+1}=\tau^{\prime}<\tau$ while ensuring that the generation $t$ agent is no worse off than what it was under the no-subsidy regime, that is, $V^{\text {opt }}\left(\tau, \tau^{\prime}\right)=V^{*}$.

(b) The combined policy of child subsidy and reduced rate of pension benefits results in a net 
increase in both fertility and total pension benefits of the generation $t$ agent.

Proof. See Appendix A.2.

Proposition 3 sketches the impact of our scheme on the generation $t$ agent. Next we demonstrate the effects on the subsequent generations. The generation $t+1$ agent faces a lower pension tax rate $\tau_{t+1}<\tau$. This lower tax rate, along with the internalization of pension externality by child care subsidy, will make the agent better off as compared to the benchmark case of no subsidy. However, similar to the generation $t$ agent, the government will decrease the rate of pension benefits of this generation $\left(\tau_{t+2}\right)$ further so that an agent of this generation also gets the same benchmark utility $V^{*}$. We continue in this way by reducing the rate of pension benefits of subsequent generations further and further while maintaining the benchmark utility $V^{*}$ throughout the phaseout period. In the following proposition we first establish that the rate of fall in pensions in this way between two consecutive generations $j$ and $j+1$ is given by $\frac{d \tau_{j+1}}{d \tau_{j}}=\frac{R}{n_{j}}$. Then we prove that fertility keeps falling throughout the phaseout period. Internalizing the pension externality through subsidy leads to a rise in fertility. However, throughout the phaseout period, as the rate of pension benefits in the old age keep on falling, the size of externality keeps on decreasing and so does the subsidy. From equation (4) note that the subsidy $\phi$ is an increasing function of the rate of pension benefit $\tau_{t+1}$. Therefore, fertility rate keeps falling throughout the phaseout period as the subsidy keeps falling. It follows that in an economy with $R>n_{t}$, that is when return on PAYG is dominated by the market return, subsequent generations' fertility is also less than $R$. So the rate of fall in pensions becomes $\frac{d \tau_{j+1}}{d \tau_{j}}=\frac{R}{n_{j}}>1$, that is, pensions keep falling at an ever-increasing rate. Hence, in an economy with $R>n_{t}$ the government can phase out PAYG pension in finite time and in a Pareto way. Finally, as both $n_{j}$ and $\tau_{j+1}$ are falling, total pension benefits of the generation $j$ agent, $p_{j+1}=\tau_{j+1} n_{j} w$, keep falling throughout the phaseout period and becomes zero in finite time. We summarize these results in the following proposition.

Proposition 4. The following results hold during the pension phaseout period.

(a) The rate of fall in pensions between two consecutive generations $j$ and $j+1$ while maintaining the benchmark utility $V^{*}$ is given by

$$
\frac{d \tau_{j+1}}{d \tau_{j}}=\frac{R}{n_{j}}
$$

(b) $\left.\frac{d n_{j}}{d \tau_{j+1}}\right|_{V=V^{*}}>0$, that is, $n_{j}$ falls with $\tau_{j+1}$ throughout the phaseout period. However, fertility never falls below the PAYG steady-state level $n^{*}$.

(c) In an economy where return on PAYG is dominated by the market return, that is $R>n_{t}$, the rate of fall in pensions is given by

$$
\frac{d \tau_{j+1}}{d \tau_{j}}=\frac{R}{n_{j}}>1 .
$$


That is, the pension tax keeps falling at an ever-increasing rate implying that pension tax reaches zero in finite time.

(d) Similar to fertility, total pension benefits also keep falling throughout the phaseout period and become zero when pension tax reaches zero in finite time.

Proof. See Appendix A.3.

\subsection{Pareto Efficiency of the Phase Out of PAYG Pensions}

Since we propose a phasing out plan of pensions in a "Pareto way", we shed some light on the concepts of Pareto efficiency under endogenous fertility. In case of exogenous fertility, the idea of Pareto is straightforward as utility of the same agent is compared across two different scenarios. However, since fertility itself changes in our model, there are new agents in the phaseout scheme who were not born in the benchmark case where PAYG program continues forever. So the usual notion of Pareto efficiency cannot be used here as it cannot tell us whether the phaseout plan is better for the "extra" number of agents born. As mentioned in the introduction, there are some recent studies dealing with the notion of Pareto efficiency under endogenous fertility. One notion is to compare utility of a representative agent across two scenarios, bypassing different population sizes across them. One such study is by Conde-Ruiz, Giménez and Pérez-Nievas (2010) which ranks allocations exclusively on preferences of those agents who are actually born and calls it Millian efficiency. Michel and Wigniolle (2007) also ranks allocations using a similar notion and call it RC-efficiency where RC stands for Representative Consumer. Golosov, Jones and Tertilt (2007) captures this way of ranking through $\mathcal{A}$-efficiency which is concerned with agents common in both the economy. Further, they provide a notion of $\mathcal{P}$-efficiency which is concerned with the utility of all potential agents in the economy. Michel and Wigniolle (2007) proposes another criterion of CRC-efficiency where CRC stands for Children for Representative Consumers according to which one allocation dominates other if it RC-dominates the other and it includes at least an equal number of children in each period. To use the $\mathcal{P}$-efficiency criterion, we need to compare the utility of unborn agents across different scenarios. Hence, we make the following assumption.

Assumption 1. Any potential agent prefers being born in a PAYG regime over remaining unborn.

Hence, there are two broad types of efficiency criterion used to rank allocations. One takes just the utility of the representative agent into account. The other type of criterion deems one allocation better than the other if it has at least as much utility and as much population as the other allocation with some agents getting strictly higher utility. With Assumption 1 above, $\mathcal{A}$-efficiency and $\mathcal{P}$-efficiency are examples of these two types. We establish in the following proposition that our phaseout plan ensures Pareto efficiency measured through both these types of criteria and this complete phaseout of PAYG is a Pareto improvement. 
Proposition 5. Phaseout of PAYG pensions followed by no PAYG is a Pareto improvement over the current scenario of $P A Y G$ pensions forever and the Pareto improvement satisfies the efficiency criteria like $\mathcal{A}$-efficiency and $\mathcal{P}$-efficiency (Golosov, Jones and Tertilt (2007)), RC and CRC efficiencies (Michel and Wigniolle (2007)) and Millian efficiency (Conde-Ruiz, Giménez and Pérez-Nievas (2010)).

Proof. See Appendix A.4.

\section{General Setup (with Endogenous Factor Prices)}

In the previous section, we have established a phaseout path of PAYG pensions under exogenous factor prices when $R>n_{t}$. In this section, we incorporate the general equilibrium effects in our analysis and demonstrate how we can reform PAYG pensions to enable transition of the economy to the long-run optimum in a Pareto way.

The dynamics in this endogenous factor prices framework is similar to that in the case of exogenous factor prices. We first establish the sub-optimality of a PAYG regime. Then, starting with an economy which is in steady-state in a PAYG regime, we exploit this sub-optimality to construct a transition path to an optimal steady-state, henceforth referred to as the $O$ steady-state. The transition path ensures that no generation is worse off. In other words, both the transition and the end-state are generated in a Pareto way. Again, by Pareto way, we mean that the proposed transition and steady-state $\mathcal{P}$-dominate the PAYG steady-state. Each generation has at least as much population as in the PAYG steady-state scenario and a representative agent in each generation gets as much utility as she would have got in the business-as-usual PAYG scenario.

\subsection{The PAYG Steady-State}

Recall that the production function in period $t$ is given by $f\left(s_{t}, n_{t-1}\right)$, where $s_{t}$ denotes capital accumulated through the savings of generation $t-1$ agents and $n_{t-1}$ is labor available for production in period $t$. In the competitive factor markets, the equilibrium wage rate and interest rate are given by the marginal products of labor and capital respectively: $w_{t}\left(s_{t}, n_{t-1}\right)=f_{2}\left(s_{t}, n_{t-1}\right)$ and $R_{t}\left(s_{t}, n_{t-1}\right)=f_{1}\left(s_{t}, n_{t-1}\right)$. With a proportional PAYG pension tax $\tau_{t}$, a generation $t$ agent in this economy solves the following problem 
taking the factor prices as given:

$$
\begin{aligned}
& \max _{\left\{s_{t+1}, n_{t}\right\}} u\left(c_{t}^{m}\right)+\beta u\left(c_{t+1}^{o}\right)+v\left(n_{t}\right) \\
& \text { subject to } \\
& \quad c_{t}^{m}=\left(1-\tau_{t}\right) w_{t}\left(s_{t}, n_{t-1}\right)-q n_{t}-s_{t+1}, \\
& \quad c_{t+1}^{o}=s_{t+1} R_{t+1}\left(s_{t+1}, n_{t}\right)+p_{t+1} .
\end{aligned}
$$

The government's budget balancing ensures $p_{t+1}=w_{t+1}\left(s_{t+1}, n_{t}\right) n_{t} \tau_{t+1}$. But, as in the last section, agents act atomistically and do not take the government's pension budget constraint into account.

Under the PAYG regime, with proportional pension tax $\tau$ in each period, let the steady-state per-capita savings and per-capita fertility be denoted by $s^{P G}$ and $n^{P G}$ respectively, while the factor prices be denoted by $w^{P G}$ and $R^{P G}$. They must satisfy the following conditions:

$$
\begin{aligned}
& u^{\prime}\left(w^{P G}(1-\tau)-q n^{P G}-s^{P G}\right)=\beta R^{P G} u^{\prime}\left(s^{P G} R^{P G}+n^{P G} w^{P G} \tau\right), \\
& q u^{\prime}\left(w^{P G}(1-\tau)-q n^{P G}-s^{P G}\right)=v^{\prime}\left(n^{P G}\right) \\
& w^{P G}=f_{2}\left(s^{P G}, n^{P G}\right) \\
& R^{P G}=f_{1}\left(s^{P G}, n^{P G}\right) .
\end{aligned}
$$

The first equation is the standard Euler equation where an atomistic agent ignores the general equilibrium effects of her choices. The second equation has an agent equalizing the marginal costs of a child with its marginal benefits. Here, along with the general equilibrium effects, the pension externality generated by a child is ignored by atomistic agents. The third and the fourth conditions characterize the factor prices in general equilibrium. Let us denote the steady-state welfare associated with the PAYG regime by $U^{P G}$.

\subsection{Suboptimality of the PAYG Steady-State}

Now we demonstrate that the PAYG steady-state has individuals making sub-optimal choices as the pension externality of children is ignored by the individuals. Let us consider the problem of maximizing the current middle-aged's utility while fixing the resources inherited by her as well as the resources left by her for the next generation at $e^{P G} \equiv$ 
$w^{P G}(1-\tau)$. This problem can be framed as

$$
\begin{gathered}
\max _{\{s, n\}} u\left(c^{m}\right)+\beta u\left(c^{o}\right)+v(n) \\
\text { subject to } \\
\quad c^{m}+q n+s \leq e^{P G}, \\
n e^{P G}+c^{o} \leq f(s, n) .
\end{gathered}
$$

While the first constraint guarantees that the total expenditure in middle age is less than the available resources $e^{P G}$, the second one ensures that the total resources made available to all the middle-aged of next generation along with the old-age consumption should not exceed the total output produced. Note that this is a concave maximization problem and the PAYG steady-state allocation is in the constraint set as it satisfies both the constraints.

Now we show that the PAYG steady-state allocation is sub-optimal as the first order conditions do not match. The first-order conditions for the above problem are

$$
\begin{aligned}
& u^{\prime}\left(c^{m}\right)=\beta f_{1}(s, n) u^{\prime}\left(c^{o}\right), \\
& \left(q+\frac{e^{P G}-f_{2}(s, n)}{f_{1}(s, n)}\right) u^{\prime}\left(c^{m}\right)=v^{\prime}(n) .
\end{aligned}
$$

While the Euler condition of intertemporal consumption is the same, the effective cost of children now includes the present value of surplus, $e^{P G}-f_{2}(s, n)$, generated by a child. This particular effect is ignored in the individual agent's optimization problem. Therefore, now the effective cost of an additional child is its direct cost $(q)$ minus the present value of pension extracted from her in the next period. Since the effective cost is less in this optimal solution, it is intuitive that the optimal allocation should have a higher number of children than the PAYG steady-state allocation, that is, $n^{o p t}>n^{P G}$, where superscript opt denotes the optimal choices. This is indeed the case and we have the following proposition.

Proposition 6. Fertility under the PAYG steady-state is sub-optimal. Fixing resources available to both the current as well as next period middle-aged at $e^{P G} \equiv w^{P G}(1-\tau)$, the current middle-aged can secure a higher utility than the PAYG level by choosing the optimal allocation with $n^{\text {opt }}>n^{P G}$. Thus, the PAYG steady-state is $\mathcal{P}$-dominated by another allocation which leaves same resources for all subsequent generations and increases fertility and utility for one generation.

Proof. See Appendix A.5. 


\subsection{Characterizing the $O$ Steady-State}

In the last subsection we showed possible welfare gains as compared to a PAYG regime. Now the question is what would be our choice of destination for this economy using these welfare gains. This is a question of distributing gains amongst different generations and potential unborn agents. As discussed in the introduction, we choose a transition of the economy in a Pareto way ending at the allocation that maximizes the steady-state welfare of a representative agent. We call this final destination the $O$ steady-state. We also ensure that this steady-state as well as the transition have at least as much fertility as the PAYG steady-state, our point of comparison. This is done to ensure that the transition and the steady-state also satisfy $\mathcal{P}$-efficiency as population is higher in each generation compared to the PAYG steady-state. In other words, the $O$ steady-state is the best $\mathcal{A}$-efficient steady-state from the class of allocations $\mathcal{P}$-dominating the PAYG steady-state. ${ }^{10}$ Another constraint is also imposed to ensure that net transfers to the old cannot be negative, that is, we guarantee a non-negative pension. From now onwards, for tractability, we assume a Cobb-Douglas functional form for the production function given by $f(s, n)=s^{\alpha} n^{1-\alpha}$.

Formally, the $O$ steady-state consumption, fertility and savings solve the following problem:

$$
\begin{aligned}
& \max _{\left\{c^{m}, c^{o}, s, n\right\}} u\left(c^{m}\right)+\beta u\left(c^{o}\right)+v(n) \\
& \text { subject to } \\
& \quad n\left(c^{m}+q n+s\right)+c^{o} \leq f(s, n), \\
& \quad n\left(c^{m}+q n+s\right) \leq f(s, n)(1-\alpha), \\
& \quad n \geq n^{P G} .
\end{aligned}
$$

The first constraint is the resource constraint which says that in any period, the total expenditure by all the middle-aged agents plus consumption of the old cannot be more than the total output produced. The second constraint says that the aggregate expenditure of the middle-aged is less than their total wage income guaranteeing that there will be a non-negative transfer to the old. The third constraint ensures that the $O$ steady-state allocation $\mathcal{P}$-dominates the PAYG steady-state allocation.

Note that the feasible set is not convex. So it is not necessary that an allocation satisfy-

\footnotetext{
10 The literature in general uses the $\mathcal{A}$-efficiency criterion while solving for the optimal steady-state allocation. See, for example, Dávila (2018) and Abio et al.(2004). However, in contrast to the more general practice of solving for the optimal steady-state allocation of the representative agent, this paper is not just solving for the optimum but is also comparing the optimum as well as the transition to the optimum to the PAYG steady-state. So, while considering Pareto improvement over the PAYG steady-state, it makes sense to take population also into account. Thus this exercise of comparing alternative scenarios should also consider fertility and use $\mathcal{P}$-efficiency to make the notion of Pareto-improvement more complete. However, adopting the other more popular criterion does not change the main transition result of this paper, that is, Proposition 8. Even considering the $\mathcal{A}$-efficiency criterion, a transition to the optimal steady-state, if it exists, can be shown in a Pareto-way.
} 
ing the first-order conditions is optimal. This concern is also pointed out by Conde-Ruiz, Giménez and Pérez-Nievas (2010). However, below we show that a solution to problem (E) exists and the first-order conditions are necessary for characterizing the optimal allocation.

For this purpose, let us denote the total resources available to a middle-aged agent by $e$. This could be used for her consumption, expenditure on children and savings for the future. Then, for a given $e$, the steady-state problem (E) can be rewritten as

$$
\begin{aligned}
& V(e)=\max _{\{s, n\}} u\left(c^{m}\right)+\beta u\left(c^{o}\right)+v(n) \\
& \text { subject to } \\
& \quad c^{m}+q n+s \leq e, \\
& n e+c^{o} \leq f(s, n), \\
& n e \leq f(s, n)(1-\alpha), \\
& n \geq n^{P G} .
\end{aligned}
$$

This is a standard concave programming problem and the optimal allocation for a given $e$ is characterized by the first-order conditions. $V(e)$ corresponds to the maximum welfare for a given $e$. Then, in order to find a solution to $(\mathrm{E})$, it suffices to find an $e \in(0, \infty)$ that maximizes $V(e)$. In the following lemma we establish the existence of such an optimal $e$, $e^{o p t}$, characterized by the first-order condition $V^{\prime}\left(e^{o p t}\right)=0$.

Lemma 1. There exists an interval $(\underline{e}, \bar{e})$ such that $e^{o p t} \in(\underline{e}, \bar{e})$ maximizes $V(e)$ and is characterized by $V^{\prime}\left(e^{o p t}\right)=0$.

Proof. See Appendix A.6.

For problem $\left(\mathrm{E}^{\prime}\right)$, let the Lagrange multipliers for the non-negative transfers to old and $\mathcal{P}$-efficiency constraints be denoted by $\mu_{1}$ and $\mu_{2}$ respectively. Since the first two constraints hold with equality, substituting for $c^{m}$ and $c^{o}$ from these constraints the firstorder conditions with respect to $s$ and $n$ respectively are

$$
\begin{aligned}
& u^{\prime}\left(c^{m}\right)=\beta u^{\prime}\left(c^{o}\right) f_{1}(s, n)+\mu_{1} f_{1}(s, n)(1-\alpha), \\
& v^{\prime}(n)=\left(q+\frac{e-f_{2}(s, n)}{f_{1}(s, n)}-\frac{\mu_{2}}{u^{\prime}\left(c^{m}\right)}+\frac{\mu_{1} e \alpha}{u^{\prime}\left(c^{m}\right)}\right) u^{\prime}\left(c^{m}\right) .
\end{aligned}
$$

In addition, we need the envelope condition corresponding to $V^{\prime}\left(e^{\text {opt }}\right)=0$ :

$$
u^{\prime}\left(c^{m}\right)=\left(\beta u^{\prime}\left(c^{o}\right)+\mu_{1}\right) n
$$


Together, equations (6(a)) and (6(b)), are the first-order conditions of the original problem (E) and characterize the optimal resources $e^{o p t}$ along with allocation $\left(c^{m}, c^{o}, s, n\right)$. Henceforth, we assume that the first-order conditions are also sufficient to characterize the optimal solution. ${ }^{11}$ The discussion leads us to the following proposition.

Proposition 7. A solution to the $O$ steady-state problem (E) exists and is characterized by the first-order conditions (6(a)) and (6(b)) along with the budget constraints. This allocation $\mathcal{P}$-dominates the PAYG steady-state allocation.

The existence of solution and its characterization by the first-order conditions have already been discussed above. The solution to problem $(\mathrm{E})$ has a floor on fertility $n^{P G}$ by construction, and it maximizes the utility of a representative agent. Thus, the second part of the proposition follows directly from the construction of problem (E).

The first equation in (6(a)) gives the first-order condition with respect to capital. If $\mu_{1}=0$, it is the standard Euler equation. However, in case the non-negative pension constraint binds, the value of capital increases as it helps to relax the non-negative pension constraint. This is what the second term on the right-hand side of the equation reflects. The second equation equates the marginal benefits of an additional child with its costs. The benefit of a child is the direct utility gain. The costs are the direct cost $q$ and the present value of the net resource $e-f_{2}(s, n)$ which must be provided to the additional child. We can also call it capital dilution since one additional child means more capital needs to be saved to maintain the same level of resources. This equation is similar to the second equation in (5) and differs only because of the presence of the two additional constraints in problem $\left(\mathrm{E}^{\prime}\right)$.

Now consider the envelope condition corresponding to $V^{\prime}\left(e^{o p t}\right)=0$ given by $u^{\prime}\left(c^{m}\right)=$ $\left(\beta u^{\prime}\left(c^{o}\right)+\mu_{1}\right) n$. If $\mu_{1}=0$, that is, if the non-negative pension constraint does not bind, then, using the Euler equation, we get

$$
n=\frac{u^{\prime}\left(c^{m}\right)}{\beta u^{\prime}\left(c^{o}\right)}=f_{1}(s, n)=R .
$$

This is the condition associated with the maximum capital level in the $O$ steady-state, that is, the 'golden rule' level of capital. However, if $\mu_{1}>0$, we have $R=f_{1}(s, n)>n .{ }^{12}$ The intuition is simple. We need some inter-generational transfer to achieve the golden

\footnotetext{
${ }^{11}$ The only issue here is the potential multiplicity of local maxima. There can be multiple $e$ 's satisfying $V^{\prime}(e)=0$. Alternatively, in problem $(\mathrm{E})$, multiple allocations can satisfy the first-order conditions as the constraint set is not convex. Thus the first-order conditions are necessary, but not sufficient. In Appendix A.8, we show sufficiency of the first-order conditions for a log utility functional form. Other papers have also shown sufficiency of the first-order conditions under certain assumptions on functional forms. See, for example, Dávila (2018) and Abio et al.(2004)

${ }^{12}$ It follows from simple algebra. When $\mu_{1}>0$, combining once again with the first equation in (6(a)), we get the following from $(6(\mathrm{~b}))$ : $u^{\prime}\left(c^{m}\right)-\left(\beta u^{\prime}\left(c^{o}\right)+\mu_{1}\right) n=0 \Rightarrow\left(\beta u^{\prime}\left(c^{o}\right)+\mu_{1}\right)\left(f_{1}(s, n)-n\right)=\mu_{1} f_{1}(s, n) \alpha>0 \Rightarrow f_{1}(s, n)>n$.
} 
rule. If that transfer is pension, we achieve that. However, if the transfer required is from the old to the middle-aged, non-negative pension prevents that. In that case, the golden rule is not achieved. Moreover, when $\mu_{1}>0$, the ratio of marginal utilities is more than $R=f_{1}(s, n)$, as can be seen from the first equation in (6(a)). Thus, the planner must intervene to ensure that an individual gets a higher return than the market when $\mu_{1}>0$. The rationale for this also follows from the inability to achieve the golden rule through inter-generational transfers. The planner needs to transfer resources from the old to the middle-aged in order to guarantee a higher capital and achieve the golden rule. But it cannot go below zero pension. When this direct transfer is not allowed, an indirect way to do that is through some incentives on saving that can guarantee a higher level of capital. Another instrument that is needed here is a child care tax or subsidy to ensure that the first-order condition with respect to $n$ also holds. We discuss the decentralized implementation of both the optimum steady-state and the transition in detail later. The above discussion is summarised in the following lemma.

Lemma 2. The O steady-state achieves the 'golden rule' (only) if it is supported by a non-negative transfer from middle-aged to old, that is, the $O$ steady-state has $R=n$ with non-negative PAYG pension. Otherwise the non-negative pension constraint binds and the $O$ steady-state has $R=f_{1}(s, n)>n$, that is, the $O$ steady-state has $R>n$ with zero $P A Y G$ pension.

So far we have characterized the $O$ steady-state. Depending on parameters, it either achieves the golden rule level of capital defined by $R=f_{1}(s, n)=n$ along with nonnegative pensions, or stops at $R=f_{1}(s, n)>n$ with zero pensions. ${ }^{13}$ Starting with a PAYG regime with resources available to the middle-aged given by $e^{P G} \equiv w^{P G}(1-\tau)$, our aim is to reach this optimal level of resources $e^{\text {opt }}$ and the corresponding allocation in a Pareto-way. Here again, by Pareto way we mean that the transition as well as the steady-state $\mathcal{P}$-dominate the PAYG steady-state. That is, each generation must have at least as much utility as in the PAYG steady-state and the population in any generation must not fall below the PAYG steady-state level of population.

\subsection{A Pareto-dominating Transition to the $O$ Steady-State}

In this section we show the existence of a transition path from the PAYG steady-state to the $O$ steady-state such that the transition path $\mathcal{P}$-dominates the PAYG steady-state. For this purpose, let us define the planner's problem for generation $j$, who receives resources

\footnotetext{
${ }^{13}$ For $\log$ utility, it can be shown that if weight $\beta$ on $c^{o}$ is greater than some threshold, the $O$ steady-state has pension and golden rule. For $\beta$ below that threshold, pension is 0 and $R>n$.
} 
$e_{j}$ and leaves behind resources $e_{j+1}$ to the next generation, as follows.

$$
W\left(e_{j}, e_{j+1}\right)=\max _{\{s, n\}} u\left(c^{m}\right)+\beta u\left(c^{o}\right)+v(n)
$$

subject to

$$
\begin{aligned}
& c^{m}+q n+s \leq e_{j}, \\
& n e_{j+1}+c^{o} \leq f(s, n), \\
& n e_{j+1} \leq f(s, n)(1-\alpha), \\
& n \geq n^{P G} .
\end{aligned}
$$

The $\mathcal{P}$-efficiency constraint and the constraint for non-negative transfers to the old are present here also. The $\mathcal{P}$-efficiency constraint ensures that, throughout the transition, fertility never falls below the PAYG level. The other constraint ensures that, throughout the transition, the PAYG type transfers from the middle-aged to the old are non-negative.

Recall that in subsection 3.2 we have shown that the PAYG steady-state is suboptimal. Each generation inherits resources $e^{P G}=w^{P G}(1-\tau)$ and leaves behind the same amount of resources for the next generation. But it does not do so optimally as it ignores the pension benefits of a child. Taking that into account, the current generation's utility can be increased beyond the PAYG steady-state level, $U^{P G}$. At the PAYG steadystate, $e_{t}=e_{t+1}=e^{P G}$, and, by definition of $W\left(e_{t}, e_{t+1}\right)$, we have $W\left(e_{t}, e_{t+1}\right)>U^{P G}$ as the externality associated with the children is taken care of. Now, since $W\left(e_{t}, e_{t+1}\right)$ is increasing in its first argument and decreasing in its second argument, $e_{t+1}$ can be increased till $W\left(e_{t}, e_{t+1}\right)=U^{P G}$. Thus, the next generation experiences a resource (disposable income) gain while the current generation is no worse off. Now generation $t+1$ has $e_{t+1}>e^{P G}$, so $e_{t+2}$ can be increased from the $e^{P G}$ level to maintain the equality $W\left(e_{t+1}, e_{t+2}\right)=U^{P G}$. Moreover, with $W\left(e_{t}, e_{t+1}\right)=W\left(e_{t+1}, e_{t+2}\right)$ and $e_{t}<e_{t+1}$, it follows that $e_{t+1}<e_{t+2}$. Thus, iterating forward from the PAYG steady-state level at time $t$, resources will move in sequence $e^{P G}=e_{t}<e_{t+1}<e_{t+2}<\ldots<e_{t+j}<\ldots$ such that $W\left(e_{t}, e_{t+1}\right)=W\left(e_{t+1}, e_{t+2}\right)=W\left(e_{t+2}, e_{t+3}\right)=\ldots=W\left(e_{t+j}, e_{t+j+1}\right)=\ldots=U^{P G}$. То reach the steady-state welfare maximizing resource level $e^{\text {opt }}$, we need to show that this sequence reaches $e^{\text {opt }}$ in finite time. Let $\hat{e}<e^{\text {opt }}$ be such that $W\left(\hat{e}, e^{\text {opt }}\right)=U^{P G}$. Then we need to show that the sequence reaches $\hat{e}$ in finite time as reaching $\hat{e}$ implies reaching $e^{o p t}$ in the next period. We establish this in the following proposition.

Proposition 8. There exists a Pareto-way of attaining the optimal allocation in finite periods. Formally, the sequence $\left\{e_{t+j}\right\}$ defined above reaches $\hat{e}$ in finite time $T$, that is, $e_{t+T} \geq \hat{e}$. Moreover, the transition $\mathcal{P}$-dominates the PAYG steady-state allocation.

Proof. See Appendix A.7. 
Thus, Proposition 8 establishes that it is possible for the planner to devise a transition plan that leads the economy to the $O$ steady-state in finite time while ensuring that each generation has at least as many children and gets as much utility that it would have gotten had the economy continued to be in the PAYG steady-state. Of course, this is a specific plan where the utility of every generation is pegged to the benchmark level $U^{P G}$. There can be alternative plans where some of the utility gains is distributed to the initial generations. In those plans, achieving the $O$ steady-state will be delayed.

\subsection{A Tax-Subsidy Regime to Implement the $O$ Steady-State and Transition}

In the last two subsections we discussed optimality in terms of a planner's desired allocation. In this subsection we discuss the policy instruments required by the planner to implement the optimal allocations for both the $O$ steady-state and the transition. We show that the required instruments are a child care tax or subsidy accompanied by either a PAYG pension or a savings subsidy.

The $O$ steady-state does not need a separate discussion as $V\left(e^{o p t}\right)$ in $\left(\mathrm{E}^{\prime}\right)$ can be written as $W\left(e^{o p t}, e^{o p t}\right)$ in $(\mathrm{F})$. In other words, the planner's problem in transition, $W\left(e_{j}, e_{j+1}\right)$, is more general and encompasses the steady-state $V(e)$ as a special case: $W(e, e)=V(e)$. We first characterize the optimal allocation for the planner's problem in transition, problem $(\mathrm{F})$.

For any $\left(e_{j}, e_{j+1}\right)$, with $\mu_{1}$, and $\mu_{2}$ being the Lagrange multipliers associated with the non-negative transfers to old and $\mathcal{P}$-efficiency constraints respectively, the first-order conditions for $(\mathrm{F})$ are given by

$$
\begin{aligned}
& u^{\prime}\left(c^{m}\right)=\beta f_{1}(s, n) u^{\prime}\left(c^{o}\right)\left(1+\frac{\mu_{1}(1-\alpha)}{\beta u^{\prime}\left(c^{o}\right)}\right), \\
& v^{\prime}(n)=\left(q+\frac{e_{j+1}-f_{2}(s, n)}{f_{1}(s, n)}-\frac{\mu_{2}}{u^{\prime}\left(c^{m}\right)}+\frac{\mu_{1} e_{j+1} \alpha}{u^{\prime}\left(c^{m}\right)}\right) u^{\prime}\left(c^{m}\right) .
\end{aligned}
$$

These first-order conditions are very similar to the first-order conditions for problem $\left(\mathrm{E}^{\prime}\right)$ given by equation (6(a)), and, in fact, boil down to the same conditions when $e_{j}=e_{j+1}=e^{o p t}$.

These conditions can be replicated in a decentralized way. To see that, consider the following problem of an individual generation $j$ agent facing a proportional labor income $\operatorname{tax} \tau_{j}$ to fund pensions, a child care subsidy of $\phi_{n, j}$ per child, a savings subsidy of $\phi_{s, j}$ 
per unit, and a lumpsum tax $T_{j}$ to finance these subsidies:

$$
\begin{aligned}
& \max _{\{s, n\}} u\left(c^{m}\right)+\beta u\left(c^{o}\right)+v(n) \\
& \text { subject to } \\
& \qquad c^{m}+\left(q-\phi_{n, j}\right) n+s\left(1-\phi_{s, j}\right) \leq w_{j}\left(1-\tau_{j}\right)-T_{j}, \\
& \quad c^{o} \leq s R_{j+1}+p_{j+1} .
\end{aligned}
$$

The government's budget constraints are $\phi_{n, j} n+\phi_{s, j} s=T_{j}$ and $p_{j+1}=n w_{j+1} \tau_{j+1}$. The first-order conditions for the above problem are

$$
\begin{aligned}
& \left(1-\phi_{s, j}\right) u^{\prime}\left(c^{m}\right)=\beta R_{j+1} u^{\prime}\left(c^{o}\right), \\
& \left(q-\phi_{n, j}\right) u^{\prime}\left(c^{m}\right)=v^{\prime}(n) .
\end{aligned}
$$

Comparing the two sets of first-order conditions, we find that an appropriately designed child care subsidy along with a savings subsidy, financed by a lumpsum tax ${ }^{14}$, can mimic the first-order conditions of the planner. The subsidies on child care and savings are given by

$$
\begin{aligned}
\phi_{s, j} & =\frac{\mu_{1}(1-\alpha)}{\beta u^{\prime}\left(c^{o}\right)+\mu_{1}(1-\alpha)} \geq 0, \\
\phi_{n, j} & =\frac{f_{2}(s, n)-e_{j+1}}{f_{1}(s, n)}+\frac{\mu_{2}}{u^{\prime}\left(c^{m}\right)}-\frac{\mu_{1} e_{j+1} \alpha}{u^{\prime}\left(c^{m}\right)} .
\end{aligned}
$$

When the non-negative pension constraint does not bind, we have $\mu_{1}=0$, so that $\phi_{s, j}=0$. That is, when there is a positive pension transfer, there is no need for a savings subsidy. Moreover, in that case, $f_{2}(s, n)>e_{j+1}$ which in turn implies that $\phi_{n, j}>0$. Thus, a positive pension is always accompanied by a positive child care subsidy. On the other hand, when the non-negative pension constraint binds, we have $f_{2}(s, n)=e_{j+1}$ and $\mu_{1}>0$, implying that the savings subsidy is positive. However, in this case, the sign of $\phi_{n, j}$ depends on the sign of $\mu_{2}-\mu_{1} e_{j+1} \alpha$. Hence, childcare can be either be taxed or subsidized. Hence, the optimal public policies involve a child care tax or subsidy accompanied by either a positive pension and no savings subsidy, or zero pension and a positive savings subsidy. Comparing with equation (6(a)), we see that we need this combination of subsidies and taxes even at the steady-state to achieve the $O$ steady-state allocation which corresponds to $e_{j}=e_{j+1}=e^{o p t}$.

The following proposition summarizes the above discussion on the policy instruments required by the planner to implement the optimal allocations.

Proposition 9. The $O$ steady-state as well as the transition to it starting from a PAYG

\footnotetext{
${ }^{14}$ We have used it as a lumpsum tax but it can also be a tax on labor in the model since labor is assumed to be inelastic.
} 
steady-state can be implemented in a decentralized way by a combination of child care tax or subsidy and one of either a PAYG pension or a subsidy on savings.

A noteworthy point is that we also need a subsidy on savings when the non-negative pension constraint binds, that is, $\mu_{1}>0$. The subsidy on savings is needed only when the non-negative pension constraint binds with $R>n$ and the golden rule is not achieved. It can be interpreted as a second-best tool to incentivise savings when the first-best option of transfer from the old to the middle-aged is not allowed.

\section{Conclusion}

For quite sometime the PAYG pension system is facing serious criticisms, mainly due to demographic shifts like a fall in fertility coinciding with a rise in longevity. Also, there is no efficiency rationale for pensions if the economy underaccumulates capital and market return dominates the return from PAYG pensions which is the fertility rate. But phasing pensions out without making any generation worse off has been a challenging task. This paper proposes a novel way out of the PAYG pension system in a Pareto way. An inefficiency within the pension system that is well acknowledged in the literature but somehow overlooked till date for the purpose of phasing pensions out, has been carefully presented in the paper. The paper combines three popular strands of literature related to PAYG pensions. The first strand identifies the externalities associated with children and provides ways to deal with it. The second strand tries to find a balance between differently directed intergenerational transfers, and it turns out that our policies have that balancing feature. The third strand of literature deals with phasing out of pensions and, in our evaluation, the present paper mostly contributes to this literature. To be precise, the paper recommends a childcare subsidy package to correct for the positive externality in a PAYG system and then takes advantage of this positive externality to propose a scheme that provides a way for subsequent generations' pension tax to be gradually reduced while ensuring that no generation is worse off than under the PAYG regime. In the process the PAYG pensions can be completely phased out in finite time, maintaining all the efficiency criteria considered in the literature in the context of endogenous fertility. 


\section{A Appendix}

\section{A.1 Proof of Proposition 1}

Proof. In the first order conditions (2) for the optimal choices, $u^{\prime}\left(c_{t}^{m}\right)$ equals $\beta R u^{\prime}\left(c_{t+1}^{o}\right)$ by the first condition. Substituting $u^{\prime}\left(c_{t}^{m}\right)$ by $\beta R u^{\prime}\left(c_{t+1}^{o}\right)$ in the second condition we get the following equation:

$$
\beta u^{\prime}\left(c_{t+1}^{o}\right)\left(R q-\tau_{t+1} w\right)=v^{\prime}\left(n_{t}\right) .
$$

Let us denote the utility of a generation $t$ agent by $V_{t}($.$) , that is, V_{t}(.) \equiv u\left(c_{t}^{m}\right)+$ $\beta u\left(c_{t+1}^{o}\right)+v\left(n_{t}\right)$, where $c_{t}^{m}$ and $c_{t+1}^{o}$ are defined in the constraints of problem (B). Then

$$
\frac{\partial V_{t}(.)}{\partial n_{t}}=-u^{\prime}\left(c_{t}^{m}\right) q+\beta u^{\prime}\left(c_{t+1}^{o}\right) \tau_{t+1} w+v^{\prime}\left(n_{t}\right)
$$

As an atomistic agent equates the first term on the right-hand side with the third term, the net marginal effect of fertility on utility, $\frac{\partial V_{t}(.)}{\partial n_{t}}$, equals $\beta u^{\prime}\left(c_{t+1}^{o}\right) \tau_{t+1} w>0$. Therefore the agent can increase her utility by modifying her fertility decision. Hence a better solution for the agent's problem exists in the neighborhood of her choices. This implies that $V_{t}^{\text {opt }}>V_{t}^{\text {ind }}$ and the agent's individualistic choices are not optimal.

Now we prove that $n_{t}^{\text {opt }}>n_{t}^{\text {ind }}$. Suppose, on the contrary, that $n_{t}^{\text {opt }} \leq n_{t}^{\text {ind }}$, that is, the optimal fertility choice $n_{t}^{o p t}$, a solution to problem (B), is less than or equal to the agent's individualistic choice $n_{t}^{\text {ind }}$, a solution to problem (A). We show that this will lead to a contradiction. Consider first the first order condition of problem (A) with respect to $n_{t}$, that is, the second equation in (1):

$$
u^{\prime}\left(c_{t}^{m}\right) q=v^{\prime}\left(n_{t}\right)
$$

For problem (B), the first order condition with respect to $s_{t}$, the first equation in (2), implies $u^{\prime}\left(c_{t+1}^{o}\right)=\frac{u^{\prime}\left(c_{t}^{m}\right)}{\beta R}$. Substituting this value of $u^{\prime}\left(c_{t+1}^{o}\right)$ in the second equation in (2) gives

$$
u^{\prime}\left(c_{t}^{m}\right)\left(q-\frac{\tau_{t+1} w}{R}\right)=v^{\prime}\left(n_{t}\right) .
$$

Individualistic and optimal choices of the agent must satisfy equations (A1) and (A2) respectively. Then, under the assumption that $n_{t}^{\text {opt }} \leq n_{t}^{\text {ind }}$, the right-hand side of equation (A2) must be greater than or equal to the right-hand side of equation (A1) by concavity 
of $v($.$) . It follows that$

$$
\begin{array}{rlr} 
& u^{\prime}\left(c_{t}^{m, o p t}\right)\left(q-\frac{\tau_{t+1} w}{R}\right) \geq u^{\prime}\left(c_{t}^{m, \text { ind }}\right) q \\
\Rightarrow & u^{\prime}\left(c_{t}^{m, o p t}\right) \geq u^{\prime}\left(c_{t}^{m, \text { ind }}\right) & \\
\Rightarrow \quad & c_{t}^{m, \text { opt }} \leq c_{t}^{m, \text { ind }} & {[\text { since } u(.) \text { is concave] }} \\
\Rightarrow & c_{t+1}^{o, \text { opt }} \leq c_{t+1}^{o, \text { ind }} . & {\left[\text { since } u^{\prime}\left(c_{t}^{m}\right)=\beta R u^{\prime}\left(c_{t+1}^{o}\right)\right]}
\end{array}
$$

Thus, under the assumption that $n_{t}^{\text {opt }} \leq n_{t}^{\text {ind }}$, optimal consumption decisions are less than the agent's individualistic consumption decisions. As the agent's optimal consumption and number of children are less in comparison with the atomistic choices, we have $V_{t}^{\text {opt }} \leq$ $V_{t}^{\text {ind }}$. This contradicts $V_{t}^{\text {opt }}>V_{t}^{\text {ind }}$. Hence, our assumption of $n_{t}^{\text {opt }} \leq n_{t}^{\text {ind }}$ is incorrect, implying that $n_{t}^{\text {opt }}>n_{t}^{\text {ind }}$.

\section{A.2 Proof of Proposition 3}

\section{A.2.1 Proof of Proposition 3(a)}

Proof. We start with $V^{i n d}(\tau, \tau)=V^{*}$. In appendix A.1 we have shown that $V^{\text {opt }}(\tau, \tau)>$ $V^{*}$. We prove this proposition by showing that $V^{o p t}\left(\tau_{t}, \tau_{t+1}\right)$ is strictly increasing in $\tau_{t+1}$. Recall that $V^{\text {opt }}\left(\tau_{t}, \tau_{t+1}\right)$ is the maximized value of the objective function in problem (B). It is clear from the agent's old age budget constraint in problem (B) that, other things remaining the same, an increase in $\tau_{t+1}$ expands the agent's budget set. Original optimal choice of $\left\{s_{t+1}, n_{t}\right\}$ being still available, an increase in $\tau_{t+1}$ certainly increases the agent's utility. Therefore, $V^{o p t}\left(\tau_{t}, \tau_{t+1}\right)$ is strictly increasing in $\tau_{t+1}$. Thus, in order to guarantee $V^{o p t}\left(\tau, \tau_{t+1}\right)=V^{*}<V^{o p t}(\tau, \tau)$, the government should decrease $\tau_{t+1}$, that is, $\tau_{t+1}<\tau$.

\section{A.2.2 Proof of Proposition 3(b)}

Proof. As a first step let us see that it would be enough if we can establish that the net effect of the combined policy of child subsidy and reduced rate of pension benefits on total pension benefits of the generation $t$ agent, $p_{t+1}=\tau_{t+1} n_{t} w$, is positive. Observe that $w$ remains unaffected by the combined policy and $\tau_{t+1}$ falls. So if we can show that $p_{t+1}=\tau_{t+1} n_{t} w$ increases, it would follow that $n_{t}$ increases. In the next step we prove that $p_{t+1}$ increases as a result of the combined policy.

Consider problem (A) where the generation $t$ agent takes her pension benefit $p_{t+1}$ as exogenous and makes her choices of fertility and savings. The choices are such that the government balances its pension budget constraint. Similarly consider problem (C) where the generation $t$ agent takes as exogenous both her pension benefit $p_{t+1}$ as well as her lump sum tax $T_{t}$ to finance the child care subsidy. Here the choices satisfy the government's subsidy-financing budget constraint and the pension budget constraint. Let us write the indirect utilities of the agent as a function of $p_{t+1}$, that is, $V^{i n d}\left(p_{t+1}\right)$ for problem (A) and $V^{o p t}\left(p_{t+1}\right)$ for problem $(\mathrm{C})$. Before the subsidy scheme was introduced, the agent's 
indirect utility was at the benchmark level $V^{*}$, and let the resultant total pension benefit be denoted by $p_{t+1}^{*}$, so that $V^{i n d}\left(p_{t+1}^{*}\right)=V^{*}$. Under the combined policy suppose that the resulting total pension benefit is $p_{t+1}^{\prime}$. Note that choices under the combined policy is the solution to problem (C) where $\tau_{t+1}$ is reduced to ensure that $V^{\text {opt }}\left(p_{t+1}^{\prime}\right)=V^{*}$. We prove that $p_{t+1}^{\prime}>p_{t+1}^{*}$. Suppose, on the contrary, that $p_{t+1}^{\prime} \leq p_{t+1}^{*}$. Then, from the budget sets for problems (A) and (C) it is clear that as long as the solution to problem (C) (with reduced $\tau_{t+1}$ ) satisfies the government's subsidy-financing budget constraint and the pension budget constraint, the solution is also feasible under problem (A). It follows that the optimal choices under problem (A) must result in strictly higher utility than the choices under the combined policy, that is, $V^{i n d}\left(p_{t+1}^{*}\right) \geq V^{i n d}\left(p_{t+1}^{\prime}\right)>V^{o p t}\left(p_{t+1}^{\prime}\right) \cdot{ }^{15}$ But this contradicts $V^{i n d}\left(p_{t+1}^{*}\right)=V^{*}=V^{o p t}\left(p_{t+1}^{\prime}\right)$. Hence, our supposition of $p_{t+1}^{\prime} \leq p_{t+1}^{*}$ is incorrect, implying that $p_{t+1}^{\prime}>p_{t+1}^{*}$.

\section{A.3 Proof of Proposition 4}

It is enough to prove parts (a) and (b) of the proposition. The remaining parts follow easily from (a) and (b) and are already discussed in the text. We prove parts (a) and (b) in the following two steps.

\section{Step 1: Proof of Proposition 4(a)}

Proof. During the pension phaseout period the generation $j$ agent faces pension $\operatorname{tax} \tau_{j}$ and for generation $j+1$ agent it is $\tau_{j+1}$. The government is always keeping an agent's utility at $V^{*}$, that is, $V^{\text {opt }}\left(\tau_{j}, \tau_{j+1}\right)=V^{*}$. Totally differentiating this equation we get

$$
-u^{\prime}\left(c_{j}^{m}\right) w d \tau_{j}+\beta u^{\prime}\left(c_{j+1}^{o}\right) n_{j} w d \tau_{j+1}=0 .
$$

Since optimal choices in $n_{j}$ and $s_{j+1}$ are made throughout the phaseout period, the indirect effects working through $n_{j}$ and $s_{j+1}$ are zero by the envelope theorem. Then, using the Euler equation $u^{\prime}\left(c_{j}^{m}\right)=\beta R u^{\prime}\left(c_{j+1}^{o}\right)$, the above equation gives

$$
\frac{d \tau_{j+1}}{d \tau_{j}}=\frac{R}{n_{j}}
$$

\section{Step 2: Proof of Proposition 4(b)}

Proof. Now we show that fertility keeps falling throughout the pension phaseout period. During the phaseout period, the government sets pension tax rates such that

$$
u\left(c_{j}^{m}\right)+\beta u\left(c_{j+1}^{o}\right)+v\left(n_{j}\right)=V^{*} .
$$

\footnotetext{
${ }^{15}$ The first inequality follows from $p_{t+1}^{*} \geq p_{t+1}^{\prime}$ and that indirect utility is increasing in pension benefits. The second (strict) inequality follows from the fact that the solutions to the optimization problems are unique as the objective function is strictly concave.
} 
Also, the government subsidy ensure that any generation $j$ agent's choices satisfy the following equations (which correspond to the first order conditions, equation (2), of the optimal choices for problem (B)):

$$
\begin{aligned}
& u^{\prime}\left(c_{j}^{m}\right)=\beta R u^{\prime}\left(c_{j+1}^{o}\right), \\
& u^{\prime}\left(c_{j}^{m}\right) q=\beta u^{\prime}\left(c_{j+1}^{o}\right) \tau_{j+1} w+v^{\prime}\left(n_{j}\right),
\end{aligned}
$$

Next we argue, invoking the implicit function theorem, that equations (A4) and (A5) implicitly define $n_{j}$ and $s_{j+1}$ as functions of the parameters of the model. Rewriting equations (A4) and (A5) as $\mathcal{A}\left(s_{j+1}, n_{j}\right)=0$ and $\mathcal{B}\left(s_{j+1}, n_{j}\right)=0$ respectively, the sufficient condition requires that $\left|\begin{array}{cc}\frac{\partial \mathcal{A}}{\partial n_{j}} & \frac{\partial \mathcal{A}}{\partial s_{j+1}} \\ \frac{\partial \mathcal{B}}{\partial n_{j}} & \frac{\partial \mathcal{B}}{\partial s_{j+1}}\end{array}\right| \neq 0$. After some algebra we derive

$$
\begin{aligned}
\left|\begin{array}{rr}
\frac{\partial \mathcal{A}}{\partial n_{j}} & \frac{\partial \mathcal{A}}{\partial s_{j+1}} \\
\frac{\partial \mathcal{B}}{\partial n_{j}} & \frac{\partial \mathcal{B}}{\partial s_{j+1}}
\end{array}\right|= & -v^{\prime \prime}\left(n_{j}\right)\left(\beta R^{2} u^{\prime \prime}\left(c_{j+1}^{o}\right)+u^{\prime \prime}\left(c_{j}^{m}\right)\right) \\
& -\beta u^{\prime \prime}\left(c_{j+1}^{o}\right) u^{\prime \prime}\left(c_{j}^{m}\right)\left(R q-\tau_{j+1} w\right)^{2}<0
\end{aligned}
$$

by strict concavity of $u($.$) and v($.$) . Hence equations (A4) and (A5) define n_{j}$ and $s_{j+1}$ as implicit functions of the parameters of the model, in particular, of the two parameters $\tau_{j}$ and $\tau_{j+1}$ that are changing during the pension phaseout period.

From the above discussion it follows that we can track the changes in the endogenous variables $c_{j}^{m}, c_{j+1}^{o}$ and $n_{j}$ due to adjustments in the parameters $\tau_{j}$ and $\tau_{j+1}$ during the phaseout period through the system of equations (A3), (A4) and (A5). In what follows we use these three equations to establish that fertility keeps falling throughout the phaseout period.

Substituting the value of $u^{\prime}\left(c_{j+1}^{o}\right)$ from (A4) into (A5), we get

$$
u^{\prime}\left(c_{j}^{m}\right)\left(R q-\tau_{j+1} w\right)=R v^{\prime}\left(n_{j}\right) .
$$

Totally differentiating (A3), (A4) and (A6) respectively, we get

$$
\begin{aligned}
& u^{\prime}\left(c_{j}^{m}\right) d c_{j}^{m}+\beta u^{\prime}\left(c_{j+1}^{o}\right) d c_{j+1}^{o}+v^{\prime}\left(n_{j}\right) d n_{j}=0, \\
& u^{\prime \prime}\left(c_{j}^{m}\right) d c_{j}^{m}=\beta R u^{\prime \prime}\left(c_{j+1}^{o}\right) d c_{j+1}^{o}, \\
& u^{\prime \prime}\left(c_{j}^{m}\right)\left(R q-\tau_{j+1} w\right) d c_{j}^{m}-w u^{\prime}\left(c_{j}^{m}\right) d \tau_{j+1}=R v^{\prime \prime}\left(n_{j}\right) d n_{j} .
\end{aligned}
$$


Substituting the value of $d c_{j+1}^{o}$ from (A8) into (A7) we get

$$
\begin{aligned}
& u^{\prime}\left(c_{j}^{m}\right) d c_{j}^{m}+u^{\prime}\left(c_{j+1}^{o}\right) \frac{u^{\prime \prime}\left(c_{j}^{m}\right)}{R u^{\prime \prime}\left(c_{j+1}^{o}\right)} d c_{j}^{m}+v^{\prime}\left(n_{j}\right) d n_{j}=0 \\
& \Rightarrow \quad d c_{j}^{m}=\frac{-v^{\prime}\left(n_{j}\right)}{u^{\prime}\left(c_{j}^{m}\right)+\frac{u^{\prime}\left(c_{j+1}^{o}\right) u^{\prime \prime}\left(c_{j}^{m}\right)}{R u^{\prime \prime}\left(c_{j+1}^{o}\right)}} d n_{j} .
\end{aligned}
$$

We substitute this expression of $d c_{j}^{m}$ in terms of $d n_{j}$ into equation (A9) to derive the expression for changes in $n_{j}$ in response to the adjustments in $\tau_{j}$ and $\tau_{j+1}$ while maintaining an agent's utility at $V^{*}$ during the phaseout period:

$$
\left.\frac{d n_{j}}{d \tau_{j+1}}\right|_{V=V^{*}}=\frac{-w u^{\prime}\left(c_{j}^{m}\right)}{\frac{\left(R q-\tau_{j+1} w\right) u^{\prime \prime}\left(c_{j}^{m}\right) v^{\prime}\left(n_{j}\right)}{u^{\prime}\left(c_{j}^{m}\right)+\frac{u^{\prime \prime}\left(c_{j}^{m}\right) u^{\prime}\left(c_{j+1}^{o}\right)}{R u^{\prime \prime}\left(c_{j+1}^{o}\right)}}+R v^{\prime \prime}\left(n_{j}\right)}>0 .
$$

The numerator is negative as it contains a negative sign and other terms including $u^{\prime}($.$) are positive. The denominator has two terms. The second term has v^{\prime \prime}()<$.0 . Hence the second term is negative. The first term has $u^{\prime \prime}()<0,. v^{\prime}()>$.0 and another term $q R-\tau_{j+1} w$. This term is the total cost of a child minus total monetary returns from the child. From equation (A6) it follows that this term is positive. This makes the first term in the denominator negative too. Each of the two terms being negative makes the denominator negative. Both the numerator and denominator of $\left.\frac{d n_{j}}{d \tau_{j+1}}\right|_{V=V^{*}}$ being negative, $n_{j}$ falls with $\tau_{j+1}$ throughout the phaseout period.

Finally we prove that fertility never falls below the PAYG steady-state level. To prove this claim, we focus on two time periods - the phaseout period and the post-phaseout period (the new steady-state with no pension). To show that fertility in a no PAYG steady-state regime is strictly greater than fertility in a PAYG steady-state regime with pension $\tau_{t}=\tau$ for all $t$, we use the first order conditions of agent (1) to prove that $\frac{d n}{d \tau}<0$. Totally differentiating the first two equations in (1) we get

$$
\begin{aligned}
& u^{\prime \prime}\left(c_{t}^{m}\right) d c_{t}^{m}=\beta R u^{\prime \prime}\left(c_{t+1}^{o}\right) d c_{t+1}^{o}, \\
& u^{\prime \prime}\left(c_{t}^{m}\right) q d c_{t}^{m}=v^{\prime \prime}\left(n_{t}\right) d n_{t} .
\end{aligned}
$$

These two equations ensure that $c_{t}^{m}, c_{t+1}^{o}$ and $n_{t}$ either increase or decrease together in response to a change in $\tau$. Moreover, for a pension tax $\tau$, combining the agent's middle-age and old-age budget constraints as a lifetime budget constraint we get

$$
c_{t}^{m}+\frac{c_{t+1}^{o}}{R}+q n_{t}=w(1-\tau)+\frac{p_{t+1}}{R} .
$$


For any $\tau>0$, net income through PAYG pension is negative for return dominated PAYG pension. So the post-phaseout period has a higher income than the PAYG pension period and both consumption and fertility are higher in the post-phaseout period as they either increase or decrease together.

To prove that fertility during the phaseout period is not lower than fertility in the PAYG period, it suffices to show that fertility in the last period of the phaseout at least equals fertility in the PAYG period as we have already established that fertility falls throughout the phaseout period. In the last period of phaseout $k, \tau_{k+1}=0$. Hence it follows from (4) that there is no government subsidy in period $k$. subsidy being zero, it follows from comparing the first order conditions that there is no difference between optimal and individualistic choices of agents in the margin. The only way differences can occur is through income effect as the agents pays and receives the same pension tax and benefit $\tau$ in the PAYG period whereas she pays some pension tax in period $k$ but does not receive any pension benefit. But this income effect is also neutralized by forcing that the agent gets the utility $V^{*}$, the benchmark utility in PAYG regime. The reason is the following. For agents making individualistic choices given a lifetime income, the indirect utility is increasing in lifetime income. Since both the PAYG generation agent and generation $k$ agent make individualistic choices and gets indirect utility $V^{*}$, their lifetime incomes must be the same. For the same lifetime income, the agent in last period of phaseout makes the same choices as an agent in PAYG regime. So, in the last period of phaseout, fertility equals fertility in a PAYG regime. This completes our argument that fertility in the phaseout period never falls below the PAYG fertility level.

\section{A.4 Proof of Proposition 5}

Proof. By construction, our phaseout plan guarantees that each agent born enjoys $V^{*}$ utility during phaseout. After the phaseout, lifetime income of a representative agent is higher than that of a representative agent in the PAYG scenario since there is no PAYG pension which was giving a lower return than the market return $R$. Thus, her utility is also higher than $V^{*}$. Hence, compared to the scenario where no phaseout was undertaken, each generation gets at least $V^{*}$ and some get more. Thus, our phaseout plan satisfies all the efficiency criteria related to representative agent, namely, $\mathcal{A}$-efficiency, RC-efficiency and Millian efficiency. On the other hand, through phaseout fertility remains greater than PAYG steady-state level and after the phaseout also, it remains greater since lifetime income is higher and children are normal goods in the model. Thus, our phaseout plan satisfies all the efficiency criteria which take fertility into account also, namely, $\mathcal{P}$ efficiency and CRC-efficiency. 


\section{A.5 Proof of Proposition 6}

Proof. The first-order conditions characterising the optimal are

$$
\begin{aligned}
& u^{\prime}\left(c^{m}\right)=\beta f_{1}(s, n) u^{\prime}\left(c^{o}\right), \\
& \left(q+\frac{e^{P G}-f_{2}(s, n)}{f_{1}(s, n)}\right) u^{\prime}\left(c^{m}\right)=v^{\prime}(n) .
\end{aligned}
$$

The PAYG steady-state has a positive pension tax. Since the disposable income of workers is less than their wage in presence of a pension tax, $e^{P G}<f_{2}\left(s^{P G}, n^{P G}\right)$ and the PAYG steady-state first-order conditions do not match with the first-order conditions under the optimal one. Thus, the PAYG allocation is sub-optimal in the sense that there is some other allocation which satisfies the first-order conditions and gives a higher utility to the current middle-aged.

The next step is to show that the optimal allocation has $n^{o p t}>n^{P G}$. Define $k=\frac{s}{n}$. We prove by ruling out the case that $n^{\text {opt }} \leq n^{P G}$. Note that $n^{\text {opt }}=n^{P G}$ is not possible as that implies $k^{o p t}=k^{P G}$ by the Euler condition. This in turn means PAYG allocation matches the optimal allocation which cannot be true as the first-order conditions are different. Next consider the case $n^{\text {opt }}<n^{P G}$ and suppose that it holds. Now either $k^{\text {opt }} \leq k^{P G}$ or $k^{\text {opt }}>k^{P G}$. We rule both cases out.

First, consider the possibility of $k^{\text {opt }} \leq k^{P G}$. If this holds, then $n^{\text {opt }}<n^{P G}$ and $k^{o p t} \leq k^{P G}$ imply

$$
\begin{aligned}
& c^{m, o p t}=e^{P G}-\left(q+k^{o p t}\right) n^{o p t} \geq c^{m, P G}=e^{P G}-\left(q+k^{P G}\right) n^{P G}, \\
& c^{o, o p t}=n^{o p t}\left(f\left(k^{o p t}, 1\right)-e^{P G}\right)<n^{P G}\left(f\left(k^{P G}, 1\right)-e^{P G}\right)=c^{o, P G} .
\end{aligned}
$$

But then, $u^{\prime}\left(c^{m}\right)=\beta f_{1}(s, n) u^{\prime}\left(c^{o}\right)=\beta f_{1}(k, 1) u^{\prime}\left(c^{o}\right)$ cannot hold for both the PAYG steady-state and optimal allocation as $k^{o p t} \leq k^{P G}$ and $c^{o, o p t}<c^{o, P G}$ imply

$$
\begin{aligned}
& \beta f_{1}\left(k^{o p t}, 1\right) u^{\prime}\left(c^{o, o p t}\right)>\beta f_{1}\left(k^{P G}, 1\right) u^{\prime}\left(c^{o, P G}\right)[\text { by concavity of u and } \mathrm{f}] \\
& \Rightarrow u^{\prime}\left(c^{m, o p t}\right)>u^{\prime}\left(c^{m, P G}\right) \Rightarrow c^{m, o p t}<c^{m, P G} .
\end{aligned}
$$

This contradicts $c^{m, o p t} \geq c^{m, P G}$ and hence $k^{o p t} \leq k^{P G}$ is ruled out.

Now consider the other case $k^{\text {opt }}>k^{P G}$. Comparing the first-order conditions for fertility for the optimal and PAYG steady-states we get

$$
\begin{aligned}
& u^{\prime}\left(c^{m, o p t}\right)=\frac{v^{\prime}\left(n^{o p t}\right)}{q+\frac{e^{P G}-f_{2}\left(k^{o p t}, 1\right)}{f_{1}\left(k^{o p t}, 1\right)}}>\frac{v^{\prime}\left(n^{P G}\right)}{q}=u^{\prime}\left(c^{m, P G}\right)\left[\text { as } n^{o p t}<n^{P G} \text { and } e^{P G}<f_{2}\left(k^{P G}, 1\right)<f_{2}\left(k^{o p t}, 1\right)\right] \\
& \Rightarrow u^{\prime}\left(c^{m, o p t}\right)>u^{\prime}\left(c^{m, P G}\right) \Rightarrow c^{m, o p t}<c^{m, P G} .
\end{aligned}
$$


On the other hand, using the Euler conditions for both the cases, we get

$$
\begin{aligned}
& u^{\prime}\left(c^{o, o p t}\right)=\frac{u^{\prime}\left(c^{m, o p t}\right)}{\beta f_{1}\left(k^{o p t}, 1\right)}>\frac{u^{\prime}\left(c^{m, P G}\right)}{\beta f_{1}\left(k^{P G}, 1\right)}=u^{\prime}\left(c^{o, P G}\right)\left[\text { as } c^{m, o p t}<c^{m, P G} \text { and } k^{o p t}>k^{P G}\right] \\
& \Rightarrow c^{o, o p t}<c^{o, P G}
\end{aligned}
$$

Thus, for $k^{o p t}>k^{P G}$, we have got consumption in both periods and fertility less in the optimal case as compared to the PAYG steady-state. This, however, is not possible as the optimal must give a higher utility than the PAYG steady-state.

Hence both $k^{\text {opt }}>k^{P G}$ and $k^{o p t} \leq k^{P G}$ are ruled out. So $n^{o p t} \leq n^{P G}$ is not possible.

\section{A.6 Proof of Lemma 1}

Proof. We first argue that there is a range, $[\underline{e}, \bar{e}]$, in which $e$ is sustainable. To see that there is a maximum level of sustainable $e$, let $e$ be the resources available to a current middle-aged agent and $e^{\prime}$ be the resources available to a next generation middle-aged. The maximum $e^{\prime}$ will correspond to zero consumption for the current middle-aged, otherwise a part of $c^{m}$ can be moved to savings to generate more resources for the next period. So $q n+s=e$. Let $s=n k$ where $k$ is capital per-capita. Then $(q+k) n=e$. Also, for $e^{\prime}$ to be maximum, $n e^{\prime}=f(s, n)(1-\alpha)$ will hold. Then, with constant returns to scale, we have

$$
e^{\prime}=f(k, 1)(1-\alpha)=f\left(\frac{e}{n}-q, 1\right)(1-\alpha)
$$

For given resources $e, e^{\prime}$ is maximum when $n$ is at its lower bound $n^{P G}$, that is, $e^{\prime} \leq$ $f\left(\frac{e}{n^{P G}}-q, 1\right)(1-\alpha)$. It follows that a steady-state level of resources $e$ is sustainable if $e \leq f\left(\frac{e}{n^{P G}}-q, 1\right)(1-\alpha)$. With diminishing returns of $f$ in its first argument and Inada conditions, there is a range of sustainable $e,[\underline{e}, \bar{e}]$, where $\underline{e}$ and $\bar{e}$ are the two solutions of $f\left(\frac{e}{n^{P G}}-q, 1\right)(1-\alpha)=e$. These $e$ 's correspond to the corners which have zero consumption in middle-age and all investment just ensuring the level $e$. Thus, an optimal $e^{o p t}$ exists by the Weierstrass theorem as the objective is to maximize a continuous function $V(e)$ in the compact interval $[\underline{e}, \bar{e}]$. Moreover, $V^{\prime}(e)>(<) 0$ at lower (upper) corners which have $c^{m}=0$ and we have the optimal $e^{o p t} \in(\underline{e}, \bar{e})$ which must satisfy $V^{\prime}(e)=0$. It follows that $e^{\text {opt }}$ maximizes the steady-state welfare.

\section{A.7 Proof of Proposition 8}

Proof. Suppose not, that is, $e_{t+j} \leq \hat{e} \forall j>0$. Then the increasing sequence is bounded above by $\hat{e}$ and must converge to $\tilde{e} \leq \hat{e}$. Remember that the sequence $\left\{e_{t+j}\right\}_{j=0}^{\infty}$ is an increasing sequence and satisfies $W(x, y)=U^{P G}$ with $x=e_{t+j}$ and $y=e_{t+j+1} \forall j \geq 0$. 
By taking limits,

$$
W\left(e_{t+j}, e_{t+j+1}\right)=U^{P G} \Rightarrow W(\tilde{e}, \tilde{e})=U^{P G} .
$$

Moreover, $W(x, y)=U^{P G}$ gives $y$ as a function of $x$. This graph of $y$ as a function of $x$ is above the 45 degree line $y=x$ for $x<\tilde{e}$ since it contains points $\left\{\left(e_{t+j}\right),\left(e_{t+j+1}\right)\right\}_{j=0}^{\infty}$ with $e_{t+j}<e_{t+j+1}<\tilde{e}$. So, for any $x<\tilde{e}, e_{t+j}<x<e_{t+j+1}$ for some $j>0$. Then

$$
W(x, y)=W\left(e_{t+j}, e_{t+j+1}\right)=U^{P G} \text { and } x>e_{t+j} \Rightarrow y>e_{t+j+1}>x .
$$

The graph crosses the 45 degree line at $x=\tilde{e}$. So, the slope $\frac{\partial y}{\partial x}<1$ at $\tilde{e}$. Let the four multipliers associated with the four constraints in $(\mathrm{F})$ be $\lambda_{1}, \lambda_{2}, \mu_{1}$, and $\mu_{2}$. By envelope condition which we explicitly derive later, totally differentiating $W(x, y)=U^{P G}$ gives

$$
\frac{\partial y}{\partial x}=\frac{\lambda_{1}(x, y)}{n(x, y)\left(\lambda_{2}(x, y)+\mu_{1}(x, y)\right)} .
$$

At $\tilde{e}$,

$$
1>\frac{\partial y}{\partial x} \Rightarrow \lambda_{1}(\tilde{e}, \tilde{e})<n(\tilde{e}, \tilde{e})\left(\lambda_{2}(\tilde{e}, \tilde{e})+\mu_{1}(\tilde{e}, \tilde{e})\right) .
$$

However, for $\tilde{e}<e^{\text {opt }}, V$ is increasing in $e$ and reaches maximum at $e^{\text {opt }}$. So, $V^{\prime}(\tilde{e})>0$. Again by envelope condition, $V^{\prime}(e)=\lambda_{1}-n\left(\lambda_{2}+\mu\right)$. Hence,

$$
V^{\prime}(\tilde{e})>0 \Rightarrow \lambda_{1}(\tilde{e}, \tilde{e})>n(\tilde{e}, \tilde{e})\left(\lambda_{2}(\tilde{e}, \tilde{e})+\mu_{1}(\tilde{e}, \tilde{e})\right)
$$

Thus there is a contradiction due to our assumption and the economy reaches $\hat{e}$ and $e^{\text {opt }}$ in finite time.

A formal derivation of envelope conditions is given below.

First we derive $\frac{\partial y}{\partial x}=\frac{\lambda_{1}}{n\left(\lambda_{2}+\mu_{1}\right)}$. For that,

$$
W(x, y)=U^{P G} \Rightarrow u(x-q n-s)+\beta u(f(s, n)-n y)+v(n)=U^{P G} .
$$

Total differentiating the above gives us

$$
u^{\prime}\left(c^{m}\right)(d x-q d n-d s)+\beta u^{\prime}\left(c^{o}\right)\left(f_{1}(s, n) d s+f_{2}(s, n) d n-y d n-n d y\right)+v^{\prime}(n) d n=0 .
$$

Substituting $\lambda_{1}=u^{\prime}\left(c^{m}\right)$ and $\lambda_{2}=\beta u^{\prime}\left(c^{o}\right)$, we get

$$
\begin{aligned}
& \lambda_{1}(d x-q d n-d s)+\lambda_{2}\left(f_{1}(s, n) d s+f_{2}(s, n) d n-y d n-n d y\right)+v^{\prime}(n) d n=0 \\
& \Rightarrow\left(\lambda_{2} f_{1}(s, n)-\lambda_{1}\right) d s+\lambda_{1} d x-n \lambda_{2} d y+\left(v^{\prime}(n)+\lambda_{2}\left(f_{2}(s, n)-y\right)-\lambda_{1} q\right) d n=0 .
\end{aligned}
$$


Further, substituting first order conditions from (7), we get

$$
-\mu_{1} f_{1}(s, n)(1-\alpha) d s+\lambda_{1} d x-\left(\mu_{2}+\mu_{1}\left(f_{2}(s, n)(1-\alpha)-y\right)\right) d n=n \lambda_{2} d y .
$$

If $n \geq n^{P G}$ binds, $d n=0$ otherwise its multiplier $\mu_{2}=0$. This implies $\mu_{2} d n=0$. Thus,

$$
\begin{aligned}
& -\mu_{1} f_{1}(s, n)(1-\alpha) d s+\lambda_{1} d x-\mu_{1}\left(f_{2}(s, n)(1-\alpha)-y\right) d n=n \lambda_{2} d y \\
& \Rightarrow \lambda_{1} d x-\mu_{1}\left[\left(f_{2}(s, n)(1-\alpha)-y\right) d n+f_{1}(s, n)(1-\alpha) d s\right]=n \lambda_{2} d y .
\end{aligned}
$$

If non-negative pension constraint does not bind, $\mu_{1}=0$ and $\frac{\partial y}{\partial x}=\frac{\lambda_{1}}{n \lambda_{2}}=\frac{\lambda_{1}}{n\left(\lambda_{2}+\mu_{1}\right)}$. Otherwise, $f(s, n)(1-\alpha)=n y$ and totally differentiating gives us

$$
\left(f_{2}(s, n)(1-\alpha)-y\right) d n+f_{1}(s, n)(1-\alpha) d s=n d y .
$$

Substituting this expression in previous equation again gives us $\frac{\partial y}{\partial x}=\frac{\lambda_{1}}{n\left(\lambda_{2}+\mu_{1}\right)}$.

The derivation of second envelope condition $V^{\prime}(e)=\lambda_{1}-n\left(\lambda_{2}+\mu_{1}\right)$ is similar. Since $V(e)=W(e, e)$, differentiating it with respect to $e$ is the same as setting $x=y$ and hence $d x=d y$ in the left hand side of (A11) and differentiating that. Then the same algebra follows.

Now we prove the second statement in the proposition. By construction, the transition ensures each generation gets at least $U^{P G}$ utility. Moreover, fertility never falls below $n^{P G}$ level and strictly exceeds $n^{P G}$ at the beginning of the transition in period $t$ when the PAYG related externality from children is taken care of. This ensures that the second claim in the proposition holds.

\section{A.8 Sufficiency of first-order conditions: the case of logarithmic utility}

We consider utility with the following functional form: $\log \left(c^{m}\right)+\beta \log \left(c^{o}\right)+\gamma \log (n)$. We need to show that first-order conditions are sufficient to characterize the solution to $(\mathrm{E})$ even though the budget set is not convex. In other words, there is a unique $e$ satisfying $V^{\prime}(e)=0$ for $V(e)$ defined in $\left(\mathrm{E}^{\prime}\right)$. We prove that in three steps. First, we prove that for a variant of $\left(\mathrm{E}^{\prime}\right)$ where only resource constraints are present, there is a unique $e$ satisfying $V^{\prime}(e)=0$. Using this result from first step, we show in the second step that for a variant of $\left(\mathrm{E}^{\prime}\right)$ where resource constraints and $\mathcal{P}$-efficiency constraint are present, there is a unique $e$ satisfying $V^{\prime}(e)=0$. Then in the third step, using the result from second step, we prove the uniqueness of $e$ satisfying $V^{\prime}(e)=0$ for $\left(\mathrm{E}^{\prime}\right)$.

\section{Step 1: Sufficiency of first order conditions when only resource constraints are present}


Proof. For unconstrained version, for any given $e$, problem is given by following.

$$
V(e)=\max _{\{k, n\}} \log \left(c^{m}\right)+\beta \log \left(c^{o}\right)+\gamma \log (n)
$$

subject to

$$
\begin{aligned}
& c^{m}+q n+s \leq e, \\
& n e+c^{o} \leq f(s, n) .
\end{aligned}
$$

Then for any $e$, the optimum $s$ and $n$ are determined by

$$
\begin{aligned}
& \frac{1}{c^{m}}=\frac{\beta f_{1}(s, n)}{c^{o}}, \\
& \frac{\gamma}{n}=\frac{q}{c^{m}}+\frac{\beta e}{c^{o}}-\frac{\beta f_{2}(s, n)}{c^{o}} .
\end{aligned}
$$

Here constant returns to scale of $f$ ensure $R=f_{1}(s, n)=f_{1}(k, 1)$ where $k=\frac{s}{n}$ is percapita capital. Substituting $c^{m}, c^{o}$ from resource constraints gives us

$$
\begin{aligned}
& \frac{1}{e-(q+k) n}=\frac{\beta f_{1}(k, 1)}{n(f(k, 1)-e)}, \\
& \frac{\gamma}{n}=\frac{\beta\left(q f_{1}(k, 1)+e-f_{2}(k, 1)\right)}{n(f(k, 1)-e)} .
\end{aligned}
$$

Note that First order condition (A12(b)) implies

$$
\begin{aligned}
& \frac{\gamma}{\beta}(f(k, 1)-e)=q f_{1}(k, 1)+e-f_{2}(k, 1) \\
& \Rightarrow \frac{\gamma}{\beta} f(k, 1)-q f_{1}(k, 1)+f_{2}(k, 1)=\frac{(\beta+\gamma) e}{\beta} .
\end{aligned}
$$

Left hand side is increasing in $k$. Hence, $k$ is increasing in $e$. Further rearranging the terms of this equation gives us

$$
f(k, 1)=\frac{q \beta}{\gamma} f_{1}(k, 1)-\frac{\beta}{\gamma} f_{2}(k, 1)+\frac{\beta+\gamma}{\gamma} e .
$$

With a Cobb-Douglas production function, this becomes

$$
\begin{aligned}
& k^{\alpha}=\frac{q \beta \alpha}{\gamma} k^{\alpha-1}-\frac{\beta(1-\alpha)}{\gamma} k^{\alpha}+\frac{\beta+\gamma}{\gamma} e \\
& \Rightarrow(\gamma+\beta(1-\alpha)) k=q \beta \alpha+(\beta+\gamma) e k^{1-\alpha} .
\end{aligned}
$$

Now First order condition (A12(a)) implies

$$
\beta f_{1}(k, 1) e=n\left[(q+k) \beta f_{1}(k, 1)+f(k, 1)-e\right]
$$




$$
\begin{aligned}
& \Rightarrow \frac{n}{R}=\frac{n}{f_{1}(k, 1)}=\frac{\beta e}{(q+k) \beta f_{1}(k, 1)+f(k, 1)-e} \\
& \Rightarrow \frac{n}{R}=\frac{\beta e}{q \beta \alpha k^{\alpha-1}+(1+\beta \alpha) k^{\alpha}-e} .
\end{aligned}
$$

Substituting $k^{\alpha}$ from (A13) in terms of $k^{\alpha-1}$ and $e$ makes $\frac{n}{R}$ of type $\frac{e}{a k^{\alpha-1}+b e}$ where $a>0$. Since, $\alpha<1$ and $k$ is increasing in $e, \frac{n}{R}$ is of type $\frac{e}{a h(e)+b e}$ where $h(e)$ is positive and decreasing in $e$. Derivative of $\frac{n}{R}$ with respect to $e$ is $\frac{a h(e)-e a h^{\prime}(e)}{(a h(e)+b e)^{2}}>0$. So, $\frac{n}{R}$ is increasing and equals 1 at some threshold $\hat{e}$.

$$
V^{\prime}(e)=\lambda_{1}-\lambda_{2} n(e)=\beta u^{\prime}\left(c^{o}(e)\right)(R(e)-n(e))>0,
$$

so, there is a cutoff $\hat{e}$ at which $V^{\prime}(e)=0 \Leftrightarrow \frac{n}{R}=1$. Below that $V^{\prime}(e)>0$ and $V^{\prime}(e)<0$ above that. Thus there is a unique $e$ satisfying $V^{\prime}(e)=0$.

Step 2: Sufficiency of first order conditions when resource constraints and $\mathcal{P}$-efficiency constraint are present

Proof. When $\mathcal{P}$-efficiency constraint is present, for a given $e$, the maximization problem is given by

$$
\begin{aligned}
& V(e)=\max _{\{k, n\}} \log \left(c^{m}\right)+\beta \log \left(c^{o}\right)+\gamma \log (n) \\
& \text { subject to } \\
& c^{m}+q n+s \leq e, \\
& n e+c^{o} \leq f(s, n), \\
& n \geq n^{P G} .
\end{aligned}
$$

We use the result in step 1 to prove $\frac{n}{R}$ is increasing in $e$. Henceforth, we call problems in steps 1 and 2 as unconstrained and constrained respectively. So, we call the optimal choice for unconstrained and constrained problems as $n^{\text {uncons }}$ and $n^{\text {cons }}$ respectively. We show that for $e_{1}<e_{2}, \frac{n\left(e_{1}\right)}{R\left(e_{1}\right)}<\frac{n\left(e_{2}\right)}{R\left(e_{2}\right)}$. There are four possible cases as follows.

First, $\mathcal{P}$-efficiency constraint does not bind at both $e_{1}$ and $e_{2}$.

In that case, constrained and unconstrained solutions are same. Therefore, by step 1 result, $\frac{n}{R}$ is greater at $e_{2}$.

Second, $\mathcal{P}$-efficiency constraint binds at both $e_{1}$ and $e_{2}$.

Then at both $e_{1}$ and $e_{2}, n=n^{P G}$. Then the capital level is given by following Euler.

$$
\frac{1}{e-(q+k) n^{P G}}=\frac{\beta f_{1}(k, 1)}{n^{P G}(f(k, 1)-e)} .
$$


It can be seen from the Euler condition that $k$ is increasing in $e$. Thus $R$ is decreasing in $e$ and with $n^{P G}$ being same at both $e_{1}, e_{2}$ with $e_{1}<e_{2}, \frac{n}{R}$ is greater at $e_{2}$.

Third, $\mathcal{P}$-efficiency constraint binds at $e_{1}$ but not at $e_{2}$.

In this case, at $e_{1}$, unconstrained problem $n^{\text {uncons }}$ is less than $n^{P G}$ which equals constrained problem $n^{\text {cons }}$, that is, $n^{\text {uncons }}<n^{P G}$. While at $e_{2}$, unconstrained problem $n^{\text {uncons }}$ equals constrained problem $n^{\text {cons }}$ and is greater than $n^{P G}$, that is $n^{\text {uncons }}>n^{P G}$. So at some $e_{3}$ in $\left(e_{1}, e_{2}\right)$, unconstrained problem $n^{\text {uncons }}$ equals $n^{P G}$. Then comparing $e_{1}$ and $e_{3}, \frac{n}{R}$ is larger at $e_{3}$ than at $e_{1}$ by second case. Comparing $e_{3}$ and $e_{2}, \frac{n}{R}$ is larger at $e_{2}$ than at $e_{3}$ by first case. Thus, $\frac{n}{R}$ is larger at $e_{2}$ than at $e_{1}$.

Fourth, $\mathcal{P}$-efficiency constraint binds at $e_{2}$ but not at $e_{1}$.

In this case, at $e_{1}$, unconstrained problem's $n^{\text {uncons }}$ equals constrained problem $n^{\text {cons }}$ and is greater than $n^{P G}$, that is $n^{\text {uncons }}>n^{P G}$. While at $e_{2}$, unconstrained problem $n$ is less than $n^{P G}$ which equals constrained problem $n$, that is, $n^{\text {uncons }}<n^{P G}$. So at some $e_{3}$ in $\left(e_{1}, e_{2}\right)$, unconstrained problem $n^{\text {uncons }}$ equals $n^{P G}$. Then comparing $e_{1}$ and $e_{3}, \frac{n}{R}$ is larger at $e_{3}$ than at $e_{1}$ by first case. Comparing $e_{3}$ and $e_{2}, \frac{n}{R}$ is larger at $e_{2}$ than at $e_{3}$ by second case. Thus, $\frac{n}{R}$ is larger at $e_{2}$ than at $e_{1}$.

Thus, we have proved that $\frac{n}{R}$ is increasing in $e$ and $V^{\prime}(e)=\beta u^{\prime}\left(c^{o}\right)(R-n)>0$ till a cutoff at which $\frac{n}{R}=1$. That cutoff is the maximizer of $V(e)$ and satisfies all the firstorder conditions. Hence, there is a unique allocation and a unique $e$ satisfying $V^{\prime}(e)=0$.

\section{Step 3: Sufficiency of first order conditions for (E)}

Proof. We need to show the sufficiency of first-order conditions, that is, there is a unique $e$ such that $V^{\prime}(e)=0$ where $V(e)$ is defined by $\left(\mathrm{E}^{\prime}\right)$. We know there is at least one $e$ satisfying $V^{\prime}(e)=0$ as at lower(upper) bound of $e, V^{\prime}(e)>(<) 0$. However, there can be more than one such $e$. We show that this is not possible by ruling out contrary cases. Suppose there exist $e_{1} \neq e_{2}$ such that $V^{\prime}\left(e_{1}\right)=V^{\prime}\left(e_{2}\right)=0$. There are three cases.

\section{First, non-negativity constraint does not bind at either $e_{1}$ or $e_{2}$.}

This is not possible as this case corresponds to step 2 where we showed that $V^{\prime}(e)=0$ for unique $e$.

Second, non-negativity constraint binds at both $e_{1}$ and $e_{2}$.

This is also not possible. We explicitly prove that there exists exactly one $e$ with $V^{\prime}(e)=0$ and non-negativity constraint binding. The first-order conditions are given by (6(a)) and $V^{\prime}(e)=0 \Leftrightarrow \lambda_{1}=\left(\lambda_{2}+\mu_{1}\right) n$. Moreover, with non-negativity constraint binding and 
$k \equiv \frac{s}{n}$

$$
\begin{aligned}
& n e=s^{\alpha} n^{1-\alpha}(1-\alpha) \Rightarrow e=k^{\alpha}(1-\alpha), \\
& c^{m}=k^{\alpha}(1-\alpha)-q n-n k \\
& c^{o}=n k^{\alpha}-n e=n k^{\alpha} \alpha,
\end{aligned}
$$

From (6(a)),

$$
\begin{aligned}
& \lambda_{1}=\lambda_{2} \alpha k^{\alpha-1}+\mu_{1}(1-\alpha) \alpha k^{\alpha-1} \\
& \Rightarrow \lambda_{1}=\lambda_{2} \alpha k^{\alpha-1}+\left(\frac{\lambda_{1}}{n}-\lambda_{2}\right)(1-\alpha) \alpha k^{\alpha-1} \quad\left(\text { using } V^{\prime}(e)=0\right) \\
& \Rightarrow \lambda_{1}\left(n-(1-\alpha) \alpha k^{\alpha-1}\right)=\lambda_{2} \alpha^{2} n k^{\alpha-1} .
\end{aligned}
$$

Substituting $\lambda_{1}=\frac{1}{c^{m}}$ and $\lambda_{2}=\frac{\beta}{c^{o}}$ from (6(a)) and $c^{m}, c^{o}$ from (A15) and (A16),

$$
\begin{aligned}
& \frac{n-(1-\alpha) \alpha k^{\alpha-1}}{k^{\alpha}(1-\alpha)-q n-n k}=\frac{\beta \alpha}{k} \\
& \Rightarrow n=\frac{\alpha(1-\alpha) k^{\alpha}(1+\beta)}{k(1+\beta \alpha)+q \beta \alpha} \equiv \alpha(1-\alpha)(1+\beta) g(k) \\
& g^{\prime}(k)=\frac{k^{\alpha-1}\left(q \beta \alpha^{2}-(1-\alpha)(1+\beta \alpha) k\right)}{(k(1+\beta \alpha)+q \beta \alpha)^{2}}
\end{aligned}
$$

From above equation, $g^{\prime}(k)>0$ when $k$ is less than some threshold. Hence, right-hand side of equation (A17) is increasing in $k$ initially and then it falls. Both at $k=0$ and $k \rightarrow \infty$, it is 0 . So, it is more than or equal to $n^{P G}$ for some interval $\left[k_{1}, k_{2}\right]$. It equals $n^{P G}$ at $k_{1}$ and $k_{2}$. Moreover, it is increasing at $k_{1}$ and decreasing at $k_{2}$. This pins down the set of feasible potential capital per-capita $\left[k_{1}, k_{2}\right]$ that satisfies $\mathcal{P}$-efficiency constraint.

From first-order condition on fertility in (6(a)),

$$
\begin{aligned}
& \frac{\gamma}{n}+\lambda_{2}\left(k^{\alpha}(1-\alpha)-e\right)+\mu_{2}+\mu_{1}\left(k^{\alpha}(1-\alpha)^{2}-e\right)=q \lambda_{1} \\
& \Rightarrow \frac{\gamma}{n}+\mu_{2}+\mu_{1}\left(k^{\alpha}(1-\alpha)^{2}-e\right)=q \lambda_{1}(\mathrm{U} \operatorname{sing} A 14) \\
& \Rightarrow \frac{\gamma}{n}+\mu_{2}-\mu_{1} \alpha k^{\alpha}(1-\alpha)=q \lambda_{1}(\text { Again using } A 14) \\
& \Rightarrow \frac{\gamma}{n}+\mu_{2}-\left(\frac{\lambda_{1}}{n}-\lambda_{2}\right) \alpha k^{\alpha}(1-\alpha)=q \lambda_{1}\left(\mathrm{U} \operatorname{sing} V^{\prime}(e)=0\right) \\
& \Rightarrow \frac{\gamma}{n}+\mu_{2}+\lambda_{2} \alpha k^{\alpha}(1-\alpha)=\left(q+\frac{\alpha k^{\alpha}(1-\alpha)}{n}\right) \lambda_{1}
\end{aligned}
$$




$$
\Rightarrow \gamma+\beta(1-\alpha)+\mu_{2} n=\frac{q n+\alpha k^{\alpha}(1-\alpha)}{k^{\alpha}(1-\alpha)-(q+k) n}\left(\text { Substituting } \lambda_{1}=\frac{1}{c^{m}} \text { and } \lambda_{2}=\frac{\beta}{c^{o}}\right) .
$$

Using expression of $n$ from (A17),

$$
\begin{aligned}
& \gamma+\beta(1-\alpha)+\mu_{2} n=\alpha \frac{q(1+\beta+\beta \alpha)+k(1+\beta \alpha)}{k(1-\alpha)-q \alpha} \equiv h(k) \\
& \Rightarrow \mu_{2} n=h(k)-(\gamma+\beta(1-\alpha)) \geq 0 .
\end{aligned}
$$

Any allocation $(k, n)$ which satisfies first-order conditions with non-negativity constraint binding is characterized by (A17) and (A19) along with $n \geq n^{P G}$. $(k, n)$ is sufficient to characterize the allocation as $e=k^{\alpha}(1-\alpha)$ and $c^{m}, c^{o}$ are pinned down by $e$ and $n$. We show that out of $k \in\left[k_{1}, k_{2}\right]$, there is at most one $k$ satisfying all these conditions. Right-hand side of equation (A18), henceforth $h(k)$, is negative for $k<\frac{q \alpha}{1-\alpha}$ and tends to infinite when $k$ tends to $\frac{q \alpha}{1-\alpha}$. After that it is decreasing. Let us consider four exhaustive cases which together ensure there is at most one $k$ such that $V^{\prime}(e)=0$.

Case 1: If $k_{1}<k_{2}<\frac{q \alpha}{1-\alpha} \Leftrightarrow h(k)<0 \forall \mathrm{k} \in\left[k_{1}, k_{2}\right]$. Then $\mu_{2}<0$ which is not possible and no allocation satisfies all conditions.

Case 2: If $k_{1}<k_{2}=\frac{q \alpha}{1-\alpha}$, only possible $k$ is $k_{2}$ otherwise $\mu_{2}<0$. Thus we get $\left(k_{2}, n^{P G}\right)$ as the allocation.

Case 3: $k_{1} \leq \frac{q \alpha}{1-\alpha}<k_{2}$. For $k \in\left[k_{1}, \frac{q \alpha}{1-\alpha}\right), h(k)-(\gamma+\beta(1-\alpha))<0$. So, no $k$ in this range satisfies (A19). For $k$ slightly larger than $\frac{q \alpha}{1-\alpha}, h(k)$ is very large and keeps decreasing with $k$ till $h\left(k_{2}\right)$. If $h\left(k_{2}\right) \geq \gamma+\beta(1-\alpha)$, for all $k \in\left(\frac{q \alpha}{1-\alpha}, k_{2}\right), \mu_{2}>0$ and $n=n^{P G}$. That means $k$ must equal $k_{2}$ which in turn means a unique pair $\left(k_{2}, n^{P G}\right)$. If $h\left(k_{2}\right)<\gamma+\beta(1-\alpha)$, then there is some $\hat{k} \in\left(\frac{q \alpha}{1-\alpha}, k_{2}\right)$ such that $h(\hat{k})=\gamma+\beta(1-\alpha)$. For $k \in\left(\frac{q \alpha}{1-\alpha}, \hat{k}\right), \mu_{2}>0$ which requires $n=n^{P G}$ which in turn requires $k=k_{1}$ or $k_{2}$. This contradicts $k \in\left(\frac{q \alpha}{1-\alpha}, \hat{k}\right) . k \in\left(\hat{k}, k_{2}\right)$ implies $\mu_{2}<0$ and is ruled out. Thus only $k$ possible is $\hat{k}$ which satisfies (A19).

Case 4: $\frac{q \alpha}{1-\alpha}<k_{1}<k_{2}$. There are two possible subcases. First $h\left(k_{2}\right)<h\left(k_{1}\right)<$ $\gamma+\beta(1-\alpha)$. This means no possible $k$ satisfying $h(k) \geq \gamma+\beta(1-\alpha)$. If $h\left(k_{2}\right)<$ $\gamma+\beta(1-\alpha)<h\left(k_{1}\right)$, there are two possibilities-(i) $\mu_{2}=0$ and $\hat{k} \in\left(k_{1}, k_{2}\right)$ satisfying $h(\hat{k})=\gamma+\beta(1-\alpha)$ and (ii) $\mu_{2}>0, n=n^{P G}$ and $k=k_{1}$. However, it can be shown that the pair $\left(k_{1}, n^{P G}\right)$ has negative $c^{m}$ and is not feasible. For this, first observe that $g^{\prime}\left(k_{1}\right)>0$ as we argued above.

$$
g^{\prime}\left(k_{1}\right)>0 \Leftrightarrow q \beta \alpha>(1-\alpha)(1+\beta \alpha) k_{1} \Rightarrow k_{1}(1-\alpha)<\frac{q \beta \alpha}{1+\beta \alpha}<q \alpha .
$$


At allocation $\left(k_{1}, n^{P G}\right), c^{m}$ is given by

$$
\begin{aligned}
& c^{m}=k_{1}^{\alpha}(1-\alpha)-\left(q+k_{1}\right) n \\
& \Rightarrow c^{m}=k_{1}^{\alpha}(1-\alpha)\left(1-\frac{\alpha(1+\beta)\left(q+k_{1}\right)}{k_{1}(1+\beta \alpha)+q \beta \alpha}\right) \quad(\operatorname{using}(\mathrm{A} 17)) \\
& \Rightarrow c^{m}=\frac{k_{1}^{\alpha}(1-\alpha)}{k_{1}(1+\beta \alpha)+q \beta \alpha}\left(k_{1}(1-\alpha)-q \alpha\right)<0 .(\text { by }(\mathrm{A} 20))
\end{aligned}
$$

Since $\mu_{2}>0$ is not possible as that needs infeasible allocation $\left(k_{1}, n^{P G}\right), \mu_{2}=0$ and $h(k)$ must equal $\gamma+\beta(1-\alpha)$ and this gives a unique $\hat{k}$ and $n$.

Thus we have showed that there can be at most one allocation $(k, n, e)$ where nonnegativity constraint binds and $V^{\prime}(e)=0$. which contradicts $V^{\prime}\left(e_{1}\right)=V^{\prime}\left(e_{2}\right)=0$.

\section{Third, non-negativity constraint binds at exactly one of $e_{1}$ or $e_{2}$.}

Suppose it binds at $e_{1}$ and not at $e_{2}$. Then $e_{2}$ is the global maximum. Moreover, with non-negative transfer constraint $e=k^{\alpha}(1-\alpha)$ binding at $e_{1}$ and its neighbourhood, problem $\left(\mathrm{E}^{\prime}\right)$ can be rewritten in neighbourhood of $e_{1}$ as

$$
V(k)=\max _{\{n\}} \log \left(k^{\alpha}(1-\alpha)-(q+k) n\right)+\beta \log \left(n k^{\alpha} \alpha\right)+\gamma \log (n)
$$

subject to

$$
n \geq n^{P G} \text {. }
$$

We converted the problem in $e$ to problem in $k$ as $e=k^{\alpha}(1-\alpha) \cdot V^{\prime}(k)=V^{\prime}(e) e^{\prime}(k)$ and both the derivatives have same sign. If at $\mathrm{k}, n \geq n^{P G}$ constraint binds,

$$
\begin{aligned}
& V^{\prime}(k)=\frac{\alpha(1-\alpha) k^{\alpha-1}-n^{P G}}{k^{\alpha}(1-\alpha)-(q+k) n^{P G}}+\frac{\beta \alpha}{k} \\
& \Rightarrow V^{\prime}(k)=\frac{\alpha(1+\beta) k^{\alpha}(1-\alpha)-(1+\alpha \beta) n^{P G} k-\beta \alpha q n^{P G}}{k\left(k^{\alpha}(1-\alpha)-(q+k) n^{P G}\right)} \\
& V^{\prime}(k)=0 \Leftrightarrow n^{P G}=\frac{\alpha(1-\alpha) k^{\alpha}(1+\beta)}{k(1+\beta \alpha)+q \beta \alpha} .
\end{aligned}
$$

This is same condition as (A17). Hence, $k$ must equal $k_{2}$ which solves above equation and was defined in previous case. Moreover, for $k<k_{2}, V^{\prime}(k)>0$ and for $k>k_{2}$, $V^{\prime}(k)<0$. This follows from our analysis in previous case. Thus, at $e_{1}, V^{\prime}\left(e_{1}\right)=0$ and $V^{\prime}(e)$ is positive (negative) for $e<(>) e_{1}$ in its neighbourhood. Now consider the other case where $n \geq n^{P G}$ does not bind. Then first order condition with $n$ gives

$$
\frac{q+k}{k^{\alpha}(1-\alpha)-(q+k) n}=\frac{\beta+\gamma}{n}
$$




$$
\Rightarrow n=\frac{\beta+\gamma}{1+\beta+\gamma} \frac{k^{\alpha}(1-\alpha)}{q+k} .
$$

Putting this value of $n$ in objective,

$$
\begin{aligned}
& V(k)=\alpha(1+2 \beta+\gamma) \log (k)-(\beta+\gamma) \log (q+k) \\
& \Rightarrow V^{\prime}(k)=\frac{\alpha(1+2 \beta+\gamma)}{k}-\frac{\beta+\gamma}{k} \\
& \Rightarrow V^{\prime}(k)=\frac{\alpha(1+2 \beta+\gamma) q+(\alpha(1+\beta)-(1-\alpha)(\beta+\gamma)) k}{k(q+k)} .
\end{aligned}
$$

For $\alpha(1+\beta)-(1-\alpha)(\beta+\gamma) \geq 0, V^{\prime}\left(e_{1}\right)=0$ is not possible. For $\alpha(1+\beta)-(1-\alpha)(\beta+\gamma)<0$, $V^{\prime}\left(e_{1}\right)=0$ means $V^{\prime}(e)$ is positive (negative) for $e<(>) e_{1}$ in its neighbourhood. Thus independent of whether $n \geq n^{P G}$ binds or not, $V^{\prime}(e)>(<) 0$ for $e<(>) e_{1}$. There are two possibilities- $e_{1}<e_{2}$ or $e_{1}>e_{2}$. If $e_{1}<e_{2}$, we have $V^{\prime}\left(e_{1}\right)=V^{\prime}\left(e_{2}\right)=0$ and for some $e_{3} \in\left(e_{1}, e_{2}\right), V^{\prime}\left(e_{3}\right)<0$. This is not possible since at $e_{2}$, non-negativity constraint is not binding. So, at $e_{4}$ slightly less than $e_{2}$, it is also not binding and at that $e_{4}, V^{\prime}\left(e_{4}\right)>0$ by step 2 where we showed that $V^{\prime}(e)>0$ for $e<e_{2}$ if non-negativity constraint is not binding at $e<e_{2}$. Thus $V^{\prime}\left(e_{4}\right)>0$ and $V^{\prime}\left(e_{3}\right)<0$ means there is some $e$ in $\left(e_{1}, e_{2}\right)$ such that $V^{\prime}(e)=0$. Thus, there are three $e^{\prime}$ s satisfying $V^{\prime}(e)=0$. On the other hand, when $e_{1}>e_{2}$, for $e_{3}$ slightly less than $e_{1}, V^{\prime}\left(e_{3}\right)>0$. Moreover, for $e_{4}$ slightly greater than $e_{2}$, $V^{\prime}\left(e_{4}\right)<0$. Thus $V^{\prime}\left(e_{4}\right)>0$ and $V^{\prime}\left(e_{3}\right)<0$ mean there is some $e$ in $\left(e_{2}, e_{1}\right)$ such that

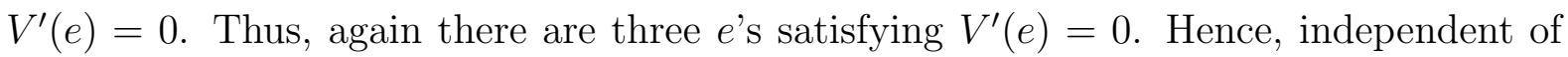
whether $e_{1}>e_{2}$ or not, at either two points, non-negative pension constraint binds or does not bind. Both these cases are not possible as we ruled them out earlier. Hence, the third case of $V^{\prime}\left(e_{1}\right)=V^{\prime}\left(e_{2}\right)=0$ and non-negativity constraint binding at exactly one of these is also ruled out. This leads us to our conclusion that for problem $\left(E^{\prime}\right)$, there is exactly one $e$ satisfying $V^{\prime}(e)=0$ and that $e$ satisfies all first-order conditions. Thus, first-order conditions are sufficient to characterize the optimal steady-state. Hence the proof. 


\section{References}

Aaron, Henry (1966). "The Social Insurance Paradox". In: The Canadian Journal of Economics and Political Science 32. 3, pp. 371-374.

Abel, Andrew B., N Gregory Mankiw, Lawrence H. Summer and Richard J. Zeckhauser (1989). "Assessing Dynamic Efficiency: Theory and Evidence". In: Review of Economic Studies 56.1, pp. 1-20.

Abio, G., G. Mahieu, and C. Patxot (2004). "On the optimality of PAYG pension systems in an endogenous fertility setting". In: Journal of Pension Economics and Finance, 3(01), pp. 35-62.

Andersen, Torben M. (2008). "Increasing longevity and social security reforms - A legislative procedure approach". In: Journal of Public Economics 92, pp. 633-646.

Andersen, Torben M. and Joydeep Bhattacharya (2011). "On myopia as rationale for social security". In: Economic Theory 47, pp. 135-158.

Andersen, Torben M. and Joydeep Bhattacharya (2017). "The Intergenerational Welfare State and the Rise and Fall of Pay-as-you-go Pensions". In: Economic Journal 127.602, pp. 896-923.

Azariadis, Costas, V. Galasso (2002). "Fiscal constitutions". In: Journal of Economic Theory, 103, pp. 255-281.

Barbie, Martin, Marcus Hagedorn, and Ashok Kaul (2004) "Assessing aggregate tests of efficiency for dynamic economies". Topics in Macroeconomics 4(1), Article 16.

Barnett, Richard C, Joydeep Bhattacharya and Mikko Puhakka (2018). "Private versus public old-age security". In: Journal of Population Economics 31.3, pp. 703-746.

Barr, Nicholas and Peter Diamond (2006). "The Economics of Pensions". In: Oxford Review of Economic Policy 22.1, pp. 15-39.

Becker, Gary S and Kevin M Murphy (1988). "The Family and the State". In: Journal of Law and Economics 31.1, pp. 1-18.

Bishnu, Monisankar (2013). "Linking consumption externalities with optimal accumulation of human and physical capital and intergenerational transfers". In: Journal of Economic Theory 148.2, pp. 720-742.

Bishnu, Monisankar, Shresth Garg, Tishara Garg and Tridip Ray (2020). "Optimal Intergenerational Transfers: Public Education and Pensions". CAMA Working Papers 2020-58, The Australian National University.

Bishnu, Monisankar and Min Wang (2017). "The Political Intergenerational Welfare State". In: Journal of Economic Dynamics and Control 77, pp. 93-110.

Boldrin, Michele and Ana Montes (2005). "The Intergenerational State Education and 
Pensions". In: Review of Economic Studies 72.3, pp. 651-664.

Boldrin, Michele and Larry E. Jones (2002). "Mortality, Fertility, and Saving in a Malthusian Economy". In: Review of Economic Dynamics 5, 775-814.

Boldrin, Michele, Mariacristina De Nardi and Larry E. Jones (2015). "Fertility and social security". In: Journal of Demographic Economics 81, 261-299.

Boldrin, Michele and Aldo Rustichini (2000). "Political Equilibria with Social Security". In: Review of Economic Dynamics 3.1, pp. 41-78.

Breyer, Friedrich (1989). "On the intergenerational Pareto efficiency of pay-as-you-go financed pension systems". In: Journal of Institutional and Theoretical Economics 145, pp. 643-658.

Browning, E. (1975). "Why the social insurance budget is too large in a democracy". In: Economic Inquiry 13, 373-388.

Caliendo, Frank, N. (2011) "Time-inconsistent preferences and social security: revisited in continuous time". In: Journal of Economic Dynamics and Control, 35, pp. 668675 .

Cigno, Alessandro (1993). "Intergenerational transfers without altruism. Family, market and state". In: European Journal of Political Economy 9, pp. 505-518.

Conde-Ruiz, J. Ignacio, Eduardo L. Giménez and Mikel Pérez-Nievas (2010). "Millian Efficiency with Endogenous Fertility". In: The Review of Economic Studies 77, pp. 154-187.

Conesa, Juan C., Krueger, Dirk. (1999). "Social security reform with heterogeneous agents". In: Review of Economic Dynamics, 2(4), 757-795.

Cordoba, Juan C. and Xiying Liu (2018). "Efficiency with Endogenous Population and Fixed Resources". In: Economics working paper series, paper no: 18017, Iowa State University.

Cooley, Thomas F. and Jorge Soares (1999). "A Positive Theory of Social Security Based on Reputation". In: The Journal of Political Economy 107.1, pp. 135-160.

Dávila, Julio (2018). "Internalizing fertility and education externalities on capital returns". In: Economic Theory 66, pp. 343-373.

de la Croix, David and Matthias Doepke (2003). "Inequality and Growth: Why Differential Fertility Matters". In: American Economic Review 93, pp. 1091-1113.

de la Croix, David and Philippe Michel (2002). "A Theory of Economic Growth, Dynamics and Policy in Overlapping Generations. New York: Cambridge University Press."

Diamond, Peter A. (1977). "A framework for social security analysis". In: Journal of Public Economics 8.3: 275-298.

Docquier, Frederic, Oliver Paddison, and Pierre Pestieau (2007). "Optimal accumulation 
in an endogenous growth setting with human capital." In: Journal of Economic Theory 134.1, pp. 361-378.

Enders, W., Lapan, H.E. (1982). "Social security taxation and intergenerational risk sharing". In: International Economic Review, 647-658.

Feldstein, Martin (1985). "The Optimal Level of Social Security Benefits". In: Quarterly Journal of Economics 100, pp. 303-320.

Feldstein, Martin (1990). "Imperfect annuity markets, unintended bequests,and the optimal age structure of social security benefits". In: Journal of Public Economics, 41(1), 31-43.

Feldstein, Martin (2005). "Rethinking Social Insurance". In: American Economic Review 95, pp. 1-24.

Fenge, R., (1995). "Pareto-efficiency of the pay-as-you-go pension system with intergenerational fairness". In: Finanzarchiv 52, 357-363.

Folbre, Nancy (1994). "Children as public goods". In: American Economic Review 84, pp. 86-90.

Friedman, Milton (1962). "Capitalism and Freedom". University of Chicago Press.

Breyer, Friedrich and Martin Straub (1993). "Welfare effects of unfunded pension systems when labor supply is endogenous". In: Journal of Public Economics 50.1, pp. 77-91.

Galasso, V., Profeta, P. (2002). "The political economy of social security: a survey". In: European Journal of Political Economy, 18, pp. 1-29.

Galor, Oded and David N. Weil (2000). "Population, Technology, and Growth: From Malthusian Stagnation to the Demographic". In: American Economic Review 90(4), pp. 806-828.

Glomm, Gerhard and Michael Kaganovich (2003). "Distributional Effects of Public Education in an Economy with Public Pensions". In: International Economic Review 44 (3), pp. 917-937.

Golosov, Mikhail, Larry E. Jones and Michèle Tertilt (2007). "Efficiency with Endogenous Population Growth". In: Econometrica 75, pp. 1039-1071.

A. İmrohoroğlu, S. İmrohoroğlu, D.H. Joines (2003). "Time inconsistent preferences and social security". In: Quarterly Journal of Economics, 118 (2), pp. 745-784

Kaganovich, M. and I. Zilcha (1999). "Education, social security, and growth." In: Journal of Public Economics, 71(2), pages 289-309.

Kaplow, L. (2006). "Myopia and the effects of social security and capital taxation on labor supply". NBER Working paper 12452.

Kotlikoff, Laurence J. (1987). "Justifying public provision of social security". In: Journal of Policy Analysis and Management, pp 674-689.

Kotlikoff, Laurence J. (2002). "Generational Policy," forthcoming in Handbook of Public 
Economics, vol. 4. Alan J. Auerbach and Martin S. Feldstein, eds. Amsterdam and NY: North-Holland.

Krueger, Dirk and Kubler, Felix. (2006). "Pareto-improving social security reform when financial markets are incomplete!?". In: American Economic Review, 96(3), 737-755.

Lambertini, L., Azariadis, C. (1998). "The fiscal politics of big governments: do coalitions matter?" Mimeo, Department of Economics, UCLA.

Lancia, F. and A. Russo (2016). "Public Education and Pensions in Democracy: A Political Economy Theory," Journal of the European Economic Association, 14(5), 1038- 1073 .

Lindbeck, Assar and Mats Persson (2003). "The Gains from Pension Reform". In: Journal of Economic Literature 41.1, pp. 74-112.

Mankiw, G., 1995. The growth of nations. Brookings Papers on Economic Activity, 275-326.

Michel, Philippe and Bertrand Wigniolle (2007). "On Efficient Child Making". In: Economic Theory 31.2, pp. 307-326.

Miles, David (1999). Modelling the Impact of Demographic Change upon the Economy. In: Economic Journal 109.452, pp. 1-36.

Mulligan, Casey B. and Xavier Sala-I-Martin (2003). "Social security, retirement, and the single-mindedness of the electorate". In: NBER Working Paper 9691.

Mulligan, Casey B. and Xavier Sala-I-Martin (2004). "Internationally common features of public old-age pensions, and their implications for models of the public sector". In: Advances in Economic Analysis and Policy, The B.E. Journal of Economic Analysis Policy, 4.

Pogue, Thomas F. and L. G. Sgontz (1977). "Social Security and Investment in Human Capital". In: National Tax Journal 30, pp. 157-169.

Rangel, Antonio (1997). "Social security reform: efficiency gains or intergenerational redistribution". Mimeo. Harvard University.

Rangel, Antonio (2003). "Forward and Backward Intergenerational Goods: Why Is Social Security Good for the Environment?". In: American Economic Review 93, pp. 813834.

Schoonbroodt, Alice, Tertilt, Michèle (2014). "Property rights and efficiency in OLG models with endogenous fertility". In: Journal of Economic Theory, 150, pp 551582.

Sinn, Hans-Werner (2000). "Pension Reform and Demographic Crisis: Why a Funded System is Needed and why it is not Needed". In: International Tax and Public 
Finance 7, pp. 389-410.

Sinn, Hans-Werner (2004). "The pay-as-you-go pension system as a fertility insurance and enforcement device". In: Journal of Public Economics, 88, pp. 1335-1357.

Smith, A. (1982). "Intergenerational transfers as social insurance". In: Journal of Public Economics, 19(1), 97-106.

van Groezen, Bas, Theo Leers, and Lex Meijdam (2003). "Social security and endogenous fertility: pensions and child allowances as Siamese twins". In: Journal of Public Economics 87, pp. 233-251.

van Groezen, Bas, and Lex Meijdam (2008). "Growing old and staying young: population policy in an ageing closed economy". In: Journal of Population Economics 21, pp. 573-588.

Verbon, H.A.A. (1988). "Conversion policies for public pensions plans in a small open economy". In: Gustafsson, B., Klevmarken, N.A. (Eds.), The Political Economy of Social Security. Elsevier Science, Amsterdam.

Zhang, Jie (1995). "Social security and endogenous growth". In: Journal of Public Economics, 58, pp. 185-213.

Zilcha, Itzhak (1991). "Dynamic Efficiency in Overlapping Generations Models with Stochastic Production". In: Journal of Economic Theory, 52(2): 364-379. 